\title{
Fidelity of the Observational/Reanalysis Datasets and Global Climate Models in Representation of Extreme Precipitation in East China
}

\author{
SICHENG HE AND JING YANG \\ State Key Laboratory of Earth Surface Process and Resource Ecology, and Academy of Disaster Reduction \\ and Emergency Management Ministry of Civil Affairs and Ministry of Education, Faculty of Geographical Science, \\ Beijing Normal University, Beijing, China \\ QING BAO \\ Institute of Atmospheric Physics, Laboratory of Numerical Modeling for Atmospheric Sciences and \\ Geophysical Fluid Dynamics(LASG), Chinese Academy of Sciences, Beijing, China

\section{LEI WANG} \\ Institute of Atmospheric Physics, Laboratory of Numerical Modeling for Atmospheric Sciences and \\ Geophysical Fluid Dynamics(LASG), Chinese Academy of Sciences, and \\ University of Chinese Academy of Science, Beijing, China \\ BIN WANG \\ Department of Atmospheric Sciences, University of Hawai'i at Mānoa, Honolulu, Hawaii
}

(Manuscript received 28 February 2018, in final form 6 October 2018)

\begin{abstract}
Realistic reproduction of historical extreme precipitation has been challenging for both reanalysis and global climate model (GCM) simulations. This work assessed the fidelities of the combined gridded observational datasets, reanalysis datasets, and GCMs [CMIP5 and the Chinese Academy of Sciences Flexible Global Ocean-Atmospheric Land System Model-Finite-Volume Atmospheric Model, version 2 (FGOALS-f2)] in representing extreme precipitation over East China. The assessment used 552 stations' rain gauge data as ground truth and focused on the probability distribution function of daily precipitation and spatial structure of extreme precipitation days. The TRMM observation displays similar rainfall intensity-frequency distributions as the stations. However, three combined gridded observational datasets, four reanalysis datasets, and most of the CMIP5 models cannot capture extreme precipitation exceeding $150 \mathrm{~mm} \mathrm{day}^{-1}$, and all underestimate extreme precipitation frequency. The observed spatial distribution of extreme precipitation exhibits two maximum centers, located over the lower-middle reach of Yangtze River basin and the deep South China region, respectively. Combined gridded observations and JRA-55 capture these two centers, but ERA-Interim, MERRA, and CFSR and almost all CMIP5 models fail to capture them. The percentage of extreme rainfall in the total rainfall amount is generally underestimated by $25 \%-75 \%$ in all CMIP5 models. Higher-resolution models tend to have better performance, and physical parameterization may be crucial for simulating correct extreme precipitation. The performances are significantly improved in the newly released FGOALS- $f 2$ as a result of increased resolution and a more realistic simulation of moisture and heating profiles. This work pinpoints the common biases in the combined gridded observational datasets and reanalysis datasets and helps to improve models' simulation of extreme precipitation, which is critically important for reliable projection of future changes in extreme precipitation.
\end{abstract}

\section{Introduction}

Extreme precipitation can have disastrous effects on human health, economy, and ecosystems (Meehl et al. 2000; Lesk et al. 2016). East China is particularly vulnerable

Corresponding author: Jing Yang, yangjing@bnu.edu.cn to extreme precipitation because of its large population and capital-intensive economy (Easterling et al. 2000; Zhai et al. 2005; Li and Wang 2017). For example, the heavy rainfall events in summer 2010 over East China affected 134 million people and caused losses of $\$ 18.0$ billion (Murray and Ebi 2012). Many studies have reported significant increases in both the intensity and 
frequency of extreme precipitation in China as a result of global warming (Zhai et al. 2005; Wang and Zhou 2005; Ma et al. 2015). Therefore, there is an urgent need for accurate forecast and projection of such events.

Global climate models (GCMs) are often used to predict future changes in extreme precipitation (e.g., Toreti et al. 2013; Li et al. 2016), although these models generally underestimate such events (Dai 2006; Huang et al. 2013, 2017; Jiang et al. 2015; Ou et al. 2013). Current projections use relative indices to estimate extreme precipitation, but they are unable to obtain the realistic changes in the absolute amounts of heavy rainfall (e.g., $>100 \mathrm{~mm} \mathrm{day}^{-1}$ ). Achieving realistic simulations of the absolute amount of extreme precipitation is an important target in the new generation of GCMs. Increasing the spatial resolution of GCMs has been reported as one method of improving simulation of extreme precipitation over land (Gao et al. 2006; Zhang et al. 2014). For example, Zhang et al. (2014) showed that models with a higher resolution have larger amounts of stratus clouds leading to a more realistic ratio of stratiform precipitation. Kimoto et al. (2005) found that higher-resolution versions of GCMs can better represent the frequency distribution of different classes of precipitation. However, an increase in spatial resolution does not always improve the simulated rainfall (e.g., Chan et al. 2013; Wang et al. 2017). The relationship between the spatial resolution of models and the quality of simulation of precipitation remains elusive.

Physical parameterizations, particularly in cumulus convection schemes (Emori et al. 2005; Huang et al. 2009; Song et al. 2012), also influence the simulation of rainfall intensity through modifying the heating rate and moisture profiles. In GCMs, moisture profiles above the boundary layer can be related to precipitation rates through influencing the transition from shallow to deep convection (Holloway and Neelin 2009; Lin et al. 2013). Different vertical structures in heating profiles may correspond to different rates of precipitation in observation and reanalysis datasets (Hagos et al. 2010; Ling and Zhang 2013). Modifying the heating profile to different shapes in GCMs can also reproduce different precipitation features (Murata and Ueno 2005; Cao and Zhang 2017). The current GCMs have biases in their heating profiles, which may also be associated with numerical descriptions of the physical processes in cumulus clouds (Tokioka et al. 1988; Stephens and Wilson 1980). The association of the distribution of moisture and the heating rate with the simulation of rainfall intensity still requires determination.

The occurrence of extreme precipitation may vary with the subseasonal progression of summer rainfall in East China from mid-May to mid-August (Tao and Chen 1987; Ding 1994; Wang et al. 2009; Yang et al. 2014). Few previous studies of extreme precipitation over East China have considered this subseasonal effect in different regions (Ding 1994; Li and Wang 2017).

This study aims to address the following questions: 1) How well is extreme precipitation over East China represented in various observational and reanalysis datasets, CMIP5 models, and a newly released highresolution model including subregional and subseasonal patterns; 2) how are the fidelity of extreme precipitation simulations associated with the spatial resolution of the models/datasets; and 3) how are the extreme precipitation simulations related to the vertical distribution of moisture and heating rate in the troposphere?

This paper is organized as follows. Section 2 describes the datasets and methods. Section 3 presents a comprehensive comparison of summer extreme precipitation over east mainland China. Section 4 discusses the plausible relationships between the simulated extreme precipitation and the summer seasonal mean and subseasonal progression of rainfall over East Asia and the relationships between the quality of simulated extreme precipitation and the models' horizontal resolution and vertical distribution of heating rate and moisture in the troposphere. A summary of the results is given in section 5 .

\section{Datasets and methods}

\section{a. Observation datasets}

Two observational datasets of rainfall were used in this study. Data from 756 rain gauge stations over East China were provided by the China Meteorological Administration (CMA; http://data.cma.cn). The homogeneity and reliability of this dataset were checked for strict quality control before its release (Chen and Sun 2017). In preprocessing, we removed the station if its value during June-August (JJA) 1998-2005 is all missing (Liu and Ren 2005). To facilitate comparison with the gridded outputs, the horizontal resolution of this observational dataset was estimated on $1^{\circ} \times 1^{\circ}$ grids based on the roughly uniform distribution of the 552 stations over East China (Fig. 1). The observational dataset from the National Aeronautics and Space Administration Tropical Rainfall Measuring Mission (TRMM 3B42) satellite provided records from April 1997 with a spatial resolution of $0.25^{\circ} \times 0.25^{\circ}$ (Huffman et al. 2007), which has been intercalibrated and bias corrected by GPCC rain gauge data using the inverse error variance weighting method (Huffman et al. 2007). Here we employed station observation datasets as the reference precipitation, because TRMM data are more reliable for tropical rainfall (Huffman 


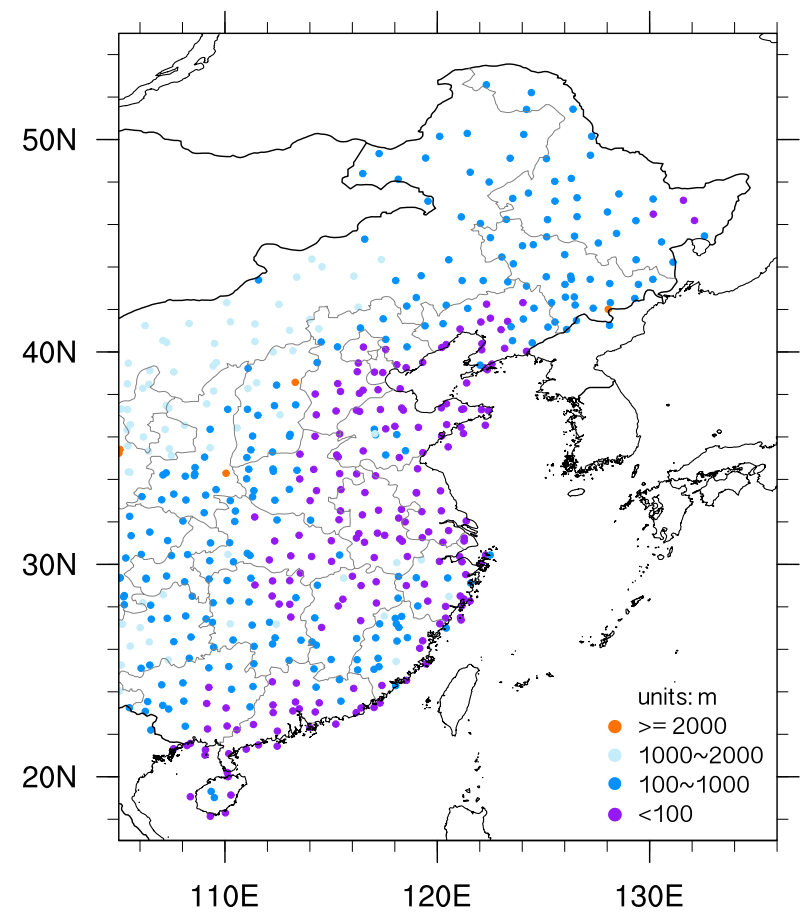

FIG. 1. Location of the 552 rain gauge stations over East China $\left(105^{\circ}-140^{\circ} \mathrm{E}, 15^{\circ}-55^{\circ} \mathrm{N}\right)$. The station elevation $(\mathrm{m})$ is denoted by the color of the dots.

et al. 2007) and have been found to overestimate the convective precipitation over southern China (Deng et al. 2015).

Three combined gridded observational datasets of rainfall were used in this study. CN05.1, with a resolution of $0.25^{\circ} \times 0.25^{\circ}$, is based on the interpolation of data from 2400 observational stations in China (Wu and Gao 2013). The Asian Precipitation-Highly Resolved Observational Data Integration Toward Evaluation of Water Resources (APHRODITE) dataset is based on rain gauge observation records over Asia with a resolution of $0.5^{\circ} \times 0.5^{\circ}$ and covers the period from 1951 to 2007 (Yatagai et al. 2009). The Precipitation Estimation from Remotely Sensed Information Using Artificial Neural Networks-Climate Data Record (PERSIANN-CDR) dataset was provided by the National Oceanic and Atmospheric Administration National Climatic Data Center and the Center for Hydrometeorology and Remote Sensing at the University of California, Irvine. This is a retrospective multisatellite precipitation dataset with a resolution of $0.25^{\circ} \times 0.25^{\circ}$ and covers the period from 1 January 1983 to 31 March 2014 (Ashouri et al. 2015; Miao et al. 2015). The interpolation method applied in CN05.1 is the "anomaly approach." The climatology is first interpolated by tinplate smoothing splines and then a gridded daily anomaly derived from angular distance weighting method is added to climatology to obtain the final CN05.1 dataset (Wu and Gao 2013). APHRODITE applied Sheremap interpolated method (Willmott et al. 1985) and the datasets used in APHRODITE included three databases: 1) Global Telecommunication System (GTS)-based data (the global summary of the day), 2) data precompiled by other projects or organizations, and 3) APHRODITE's own collection (Yatagai et al. 2012). PERSIANN-CDR used stage IV precipitation data, Gridded Satellite infrared data (GridSat-B1), and GPCP datasets. The PERSIANN algorithm is applied to the historical archive of GridSat-B1 infrared window observations from geostationary Earth orbiting (GEO) satellites, and then used GPCP monthly product to remove the biases. Last, adjusted rain-rate precipitation data are accumulated to the daily scale to produce the PERSIANN-CDR product (Ashouri et al. 2015).

\section{b. Reanalysis datasets}

Four reanalysis rainfall datasets were also evaluated. The European Centre for Medium-Range Weather Forecasts (ECMWF) interim reanalysis (ERA-Interim) dataset (Dee et al. 2011) has a resolution of $0.75^{\circ} \times 0.75^{\circ}$. The Japanese 55-year Reanalysis (JRA-55) dataset from the Japan Meteorological Agency has a resolution of $1.25^{\circ} \times 1.25^{\circ}$ (Kobayashi et al. 2015). The Modern-Era Retrospective Analysis for Research and Applications (MERRA) dataset from the National Climate Data Center, National Oceanic and Atmospheric Administration (NOAA) has a horizontal resolution of $0.67^{\circ}$ longitude $\times 0.5^{\circ}$ latitude (Rienecker et al. 2011). The National Centers for Environmental Prediction Climate Forecast System Reanalysis (CFSR) dataset was obtained from a coupled atmosphere-ocean-land surfacesea ice system from 1979 to 2010 at a resolution of $0.5^{\circ} \times$ $0.5^{\circ}$ (Saha et al. 2010).

\section{c. Model outputs}

Simulated daily rainfall outputs were retrieved from CMIP5 historical experiments using 13 GCMs (Table 1). All the analyses in this study were based on the first ensemble member of each model (r1i1p1) for all historical experiments.

A newly released high-resolution coupled model output (Table 1) was also evaluated. The Chinese Academy of Sciences (CAS) Flexible Global Ocean-Atmospheric Land System Model-Finite-Volume Atmospheric Model (FAMIL), version 2 (FGOALS-f2), is a coupled global climate model developed by the State Key Laboratory of Numerical Modeling for Atmospheric Sciences and Geophysical Fluid Dynamics, Institute of Atmospheric Physics, Chinese Academy of Sciences, Beijing, China (Haarsma et al. 2016). The FGOALS-f2 version used in 
TABLE 1. Datasets, acronyms, and horizontal resolution of the 13 CMIP5 models and FGOALS-f2 used in this study.

\begin{tabular}{llc}
\hline \hline \multicolumn{1}{c}{ Dataset } & \multicolumn{1}{c}{ Institute and country } & Horizontal resolution \\
\hline CanESM2 & Canadian Centre for Climate Modelling and Analysis, Canada & $2.8125^{\circ} \times 2.8125^{\circ}$ \\
CMCC-CM & Centro Euro-Mediterraneo sui Cambiamenti Climatici, Italy & $0.75^{\circ} \times 0.75^{\circ}$ \\
CNRM-CM5 & Centre National de Recherches Météorologiques/Centre Européen & $1.4^{\circ} \times 1.4^{\circ}$ \\
& de Recherche et Formation Avancée en Calcul Scientifique, France & $1.67^{\circ} \times 2.8125^{\circ}$ \\
FGOALS-g2 & LASG, Institute of Atmospheric Physics, CAS and Center for Earth & $1.67^{\circ} \times 2.8125^{\circ}$ \\
& System Science (CESS), Tsinghua University, China & $2.0^{\circ} \times 2.5^{\circ}$ \\
FGOALS-s2 & LASG, Institute of Atmospheric Physics, CAS, China & $2.46^{\circ} \times 3.75^{\circ}$ \\
GFDL CM3 & NOAA Geophysical Fluid Dynamics Laboratory, United States & $1.5^{\circ} \times 2.0^{\circ}$ \\
HadCM3 & Met Office Hadley Centre, United Kingdom & $1.875^{\circ} \times 3.75^{\circ}$ \\
INM-CM4.0 & Institute of Numerical Mathematics, Russia & $1.4^{\circ} \times 1.4^{\circ}$ \\
IPSL-CM5B-LR & L'Institut Pierre-Simon Laplace, France & \\
MIROC5 & University of Tokyo, National Institute for Environmental Studies & $1.875^{\circ} \times 1.875^{\circ}$ \\
& and Japan Agency for Marine-Earth Science and Technology, & $1.125^{\circ} \times 1.125^{\circ}$ \\
MPI-ESM-LR & Japan & $1.875^{\circ} \times 2.5^{\circ}$ \\
MRI-CGCM3 & Max Planck Institute for Meteorology (MPI-M), Germany & $1.0^{\circ} \times 1.0^{\circ}$ \\
NorESM1-M & Meteorological Research Institute, Japan & \\
CAS FGOALS-f2 & Norwegian Climate Centre (NorClim), Norway & \\
\hline
\end{tabular}

this study has been applied at the China National Climate Center for real-time subseasonal to seasonal prediction. The atmospheric component of FGOALS-f2 is the FAMIL component. Compared with the previous version of FGOALS-s2 used in CMIP5, the dynamic core in FGOALS-f2 has changed from spectral on a longitude-latitude grid to finite volume on a cubedsphere grid (Lin and Rood 1996; Lin 2004; Zhou et al. 2015), and the spatial resolution has been increased to $1^{\circ} \times 1^{\circ}$ and $0.25^{\circ} \times 0.25^{\circ}$. This model was used in the High Resolution Model Intercomparison Project, version 1 (HighResMIP v1.0) for CMIP6 (Haarsma et al. 2016). Another updated scheme in FGOALS-f2 is a resolving convective precipitation parameterization (copyright 2017, FAMIL Development Team, 2017SR01701) in which the convective precipitation and stratiform precipitation are explicitly calculated instead of conventional convective parameterization.

\section{d. Methodology}

Based on the common available record of the datasets, we chose the period from 1998 to 2005 for all datasets and focused on the summer season of JJA. The domain of east mainland China $\left(105^{\circ}-140^{\circ} \mathrm{E}, 15^{\circ}-55^{\circ} \mathrm{N}\right)$ was considered. Following the definition of different precipitation patterns used by the China Meteorological Administration and in other studies (e.g., Matsumoto et al. 1999), we selected $50 \mathrm{~mm} \mathrm{day}^{-1}$ as the threshold for extreme precipitation. To avoid the effect of resolution on our results, we interpolated all the datasets onto a $1^{\circ} \times 1^{\circ}$ grid in accordance with the station observation dataset using the nearest-neighbor interpolation method (Accadia et al. 2003). All the datasets are daily precipitation.
To describe the distribution of precipitation as a function of intensity (named as the frequency-intensity distribution), the frequency of precipitation was plotted against the daily precipitation rate at $1 \mathrm{~mm}^{-1 a y}{ }^{-1}$ intervals, beginning from $0.5 \mathrm{~mm} \mathrm{day}^{-1}$, and the domain average was calculated (Zhang and Chen 2016). For example, the frequency for an intensity of $1 \mathrm{~mm} \mathrm{day}^{-1}$ is the frequency of precipitation in the range $0.5-1.5 \mathrm{~mm}^{-1 a y}{ }^{-1}$. Because extreme precipitation rarely occurs over northeastern China (e.g., Fig. 3 in Zhao et al. 2013), the domain was focused over east mainland China $<35^{\circ} \mathrm{N}$. The frequency-intensity distribution, particularly for heavy rainfall, is a little bit sensitive to the precision of the data, and therefore we used the same floating type of precipitation rate to unify the frequency comparison.

To examine the spatial distribution of extreme precipitation (section 3b), the frequency was taken as the total days of extreme precipitation during the whole summer season (JJA). The total amount of extreme precipitation and the total of all precipitation were calculated, and the contribution of extreme precipitation to the total was calculated as a percentage. All of these values were calculated in each grid.

\section{Summer extreme precipitation over East China}

\section{a. Distribution of precipitation frequency as a function of intensity}

The rainfall frequency-intensity distribution over East China was compared among different datasets, with a focus on extreme precipitation. The frequency of daily precipitation is a function of the intensity of 

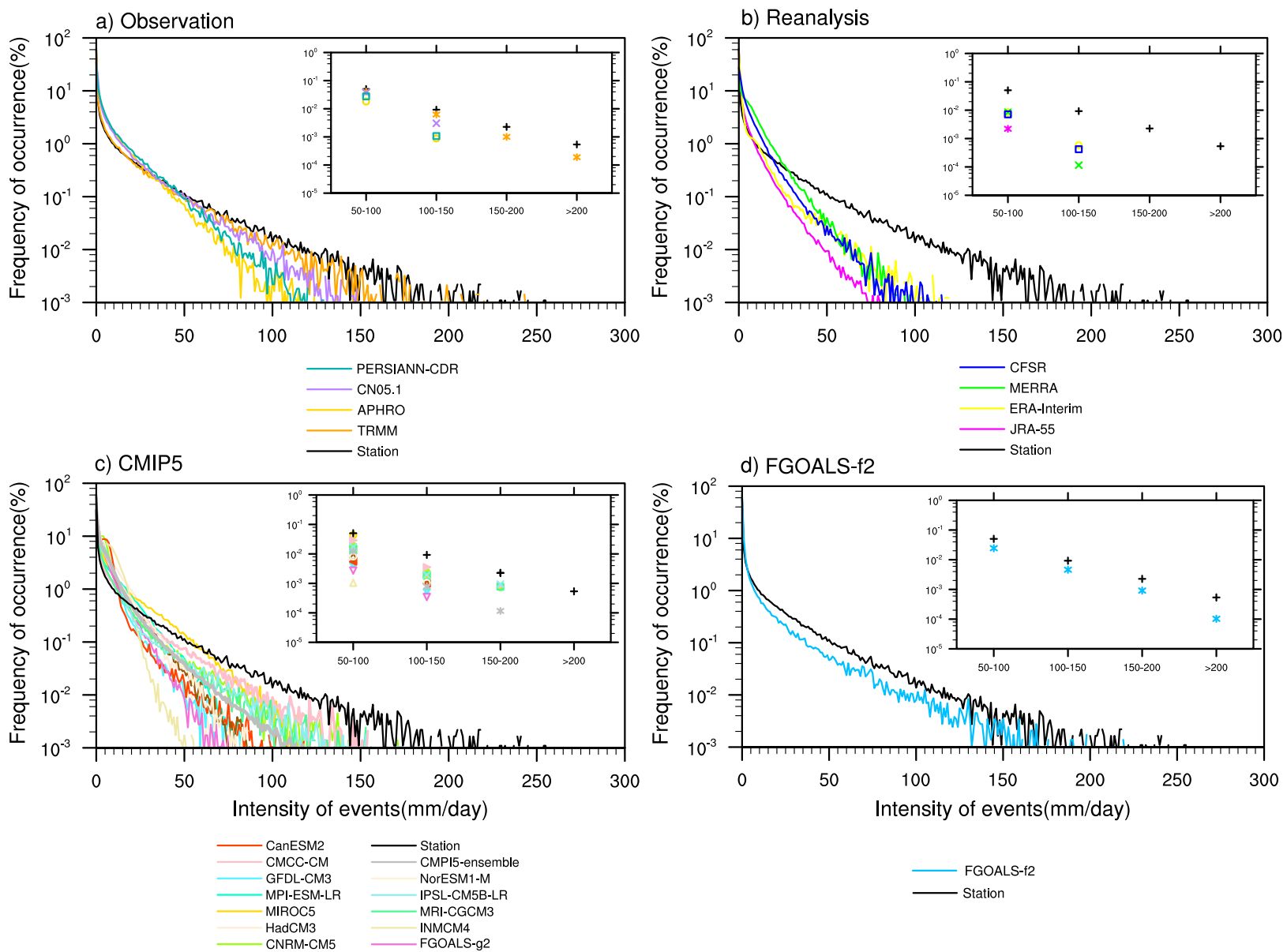

FIG. 2. Summer (JJA) rainfall frequency-intensity distribution in the (a) observation, (b) reanalysis, (c) CMIP5, and (d) FGOALS-f2 datasets. The domain is east mainland China $\left(105^{\circ}-140^{\circ} \mathrm{E}, 15^{\circ}-35^{\circ} \mathrm{N}\right)$.

precipitation from 0 to $300 \mathrm{~mm}^{-1 a y}{ }^{-1}$, which decreases as the intensity increases. Different datasets showed different frequency-intensity distributions (Fig. 2).

Among ground station datasets (Fig. 2a), the frequency of precipitation between 50 and $100 \mathrm{~mm} \mathrm{day}^{-1}$ ranges from $10^{-1}$ to $2 \times 10^{-2}$, equivalent to $4-30$ times a year; the frequency of precipitation between 100 and $150 \mathrm{~mm} \mathrm{day}^{-1}$ is between $2 \times 10^{-2}$ and $10^{-3}$, equivalent to nearly $1-5$ times a year; and heavy rainfall $>200 \mathrm{~mm} \mathrm{day}^{-1}$ had a frequency of nearly $10^{-3}$, equivalent to once every three years. In the TRMM dataset, the frequency of different intensities of rainfall showed a similar distribution but is generally lower than in the gauge observation. The frequencies of extreme precipitation are underestimated by three combined gridded observational rainfall products, CN05.1, APHRODITE, and PERSIANN-CDR, which did not capture extreme precipitation $>150 \mathrm{~mm} \mathrm{day}^{-1}$. The frequency of rainfall events between 50 and $100 \mathrm{~mm}^{-1}{ }^{-1}$ ranges from $10^{-1}$ to $10^{-2}$ in CN05.1, almost half the frequency in the gauge observations, and from $10^{-1}$ to $10^{-3}$ in the PERSIANN-CDR and APHRODITE datasets, less than half that of the gauge observations. The frequency of rainfall events between 100 and $150 \mathrm{~mm}^{-1}$ day $^{-1}$ ranges from $10^{-2}$ to $10^{-3}$ for $\mathrm{CN} 05.1$, about $20 \%$ of the frequency in the gauge observations, and is $10^{-3}$ for the PERSIANN-CDR and APHRODITE datasets, about $10 \%$ of the frequency in the gauge observations.

Four reanalysis datasets (CFSR, MERRA, ERAInterim, and JRA-55) showed much lower frequencies of heavy rainfall events than the gauge observations (Fig. 2b). In ERA-Interim and CFSR datasets, the events of about $50 \mathrm{~mm} \mathrm{day}^{-1}$ had a frequency of about $20 \%\left(2 \times 10^{-2}\right)$ of that for the gauge observational datasets, whereas events of about $100 \mathrm{~mm} \mathrm{day}^{-1}$ had a frequency of about $10 \%\left(2 \times 10^{-3}\right)$ of that for the gauge observational datasets. In MERRA, events of about $50 \mathrm{~mm} \mathrm{day}^{-1}$ had a frequency of about $40 \%\left(4 \times 10^{-2}\right)$ of that for the gauge observational datasets, whereas events of about $100 \mathrm{~mm}$ day $^{-1}$ had a frequency of about $5 \%\left(10^{-3}\right)$ of that for the gauge observational 


\section{(a) Observation}

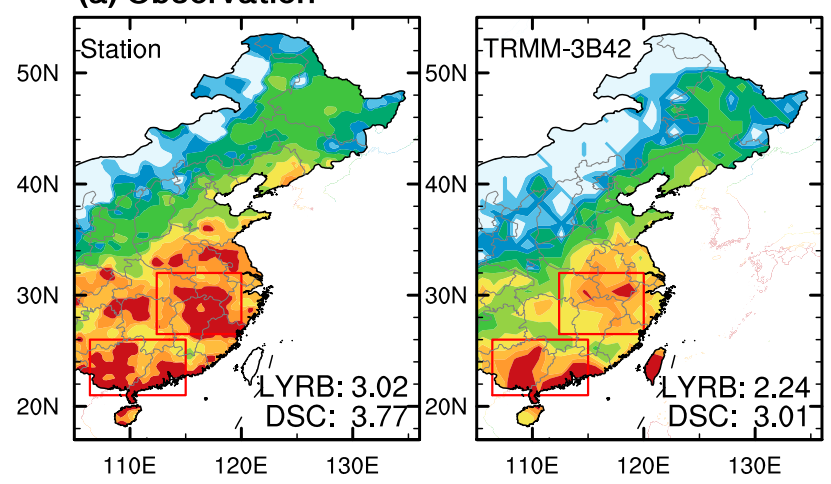

\section{(b) Combined gridded observation}
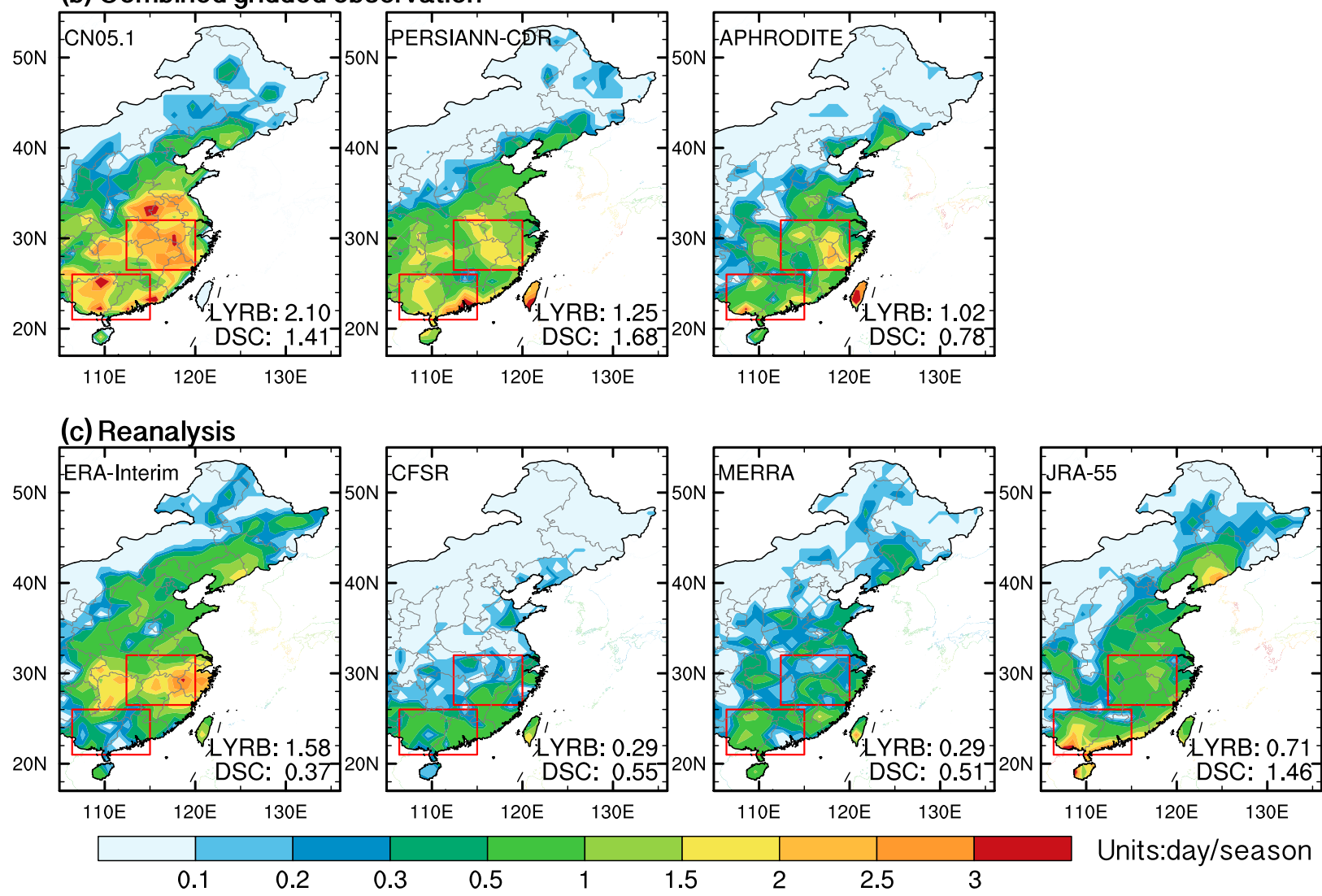

FIG. 3. JJA frequency of extreme precipitation in (a) observation, (b) combined gridded observation datasets, and (c) reanalysis datasets. The red boxes represent the two centers of maximum frequency of extreme precipitation: the LYRB center $\left(26.5^{\circ}-32^{\circ} \mathrm{N}, 112.5^{\circ}-\right.$ $\left.120^{\circ} \mathrm{E}\right)$ and the DSC center $\left(21^{\circ}-26^{\circ} \mathrm{N}, 116.4^{\circ}-115^{\circ} \mathrm{E}\right)$. The numbers at the bottom right denote the domain-averaged frequency over the LYRB and DSC, respectively.

datasets. JRA-55 had a frequency of about $10 \%\left(10^{-2}\right)$ of that for the gauge observational datasets over $50 \mathrm{~mm} \mathrm{day}^{-1}$ and cannot capture extreme precipitation $>80 \mathrm{~mm}$ day $^{-1}$. MERRA, CFSR, and ERA-Interim datasets cannot capture extreme precipitation $>120 \mathrm{~mm} \mathrm{day}^{-1}$.

Among CMIP5 outputs (Fig. 2c), all 13 models underestimated the frequency of extreme precipitation compared with the gauge observational datasets. The multimodel ensemble (MME) results showed that the frequency of rainfall $>50 \mathrm{~mm} \mathrm{day}^{-1}$ in the models is much lower than the observed frequency, with a frequency from $10^{-2}$ to $10^{-3}$ for events of $50-100 \mathrm{~mm} \mathrm{day}^{-1}(1 \%-50 \%$ of the observed frequency) and $10^{-3}$ for events of $100-150 \mathrm{~mm} \mathrm{day}^{-1}$ ( $6 \%-60 \%$ of the observed frequency). Of the 13 models, 


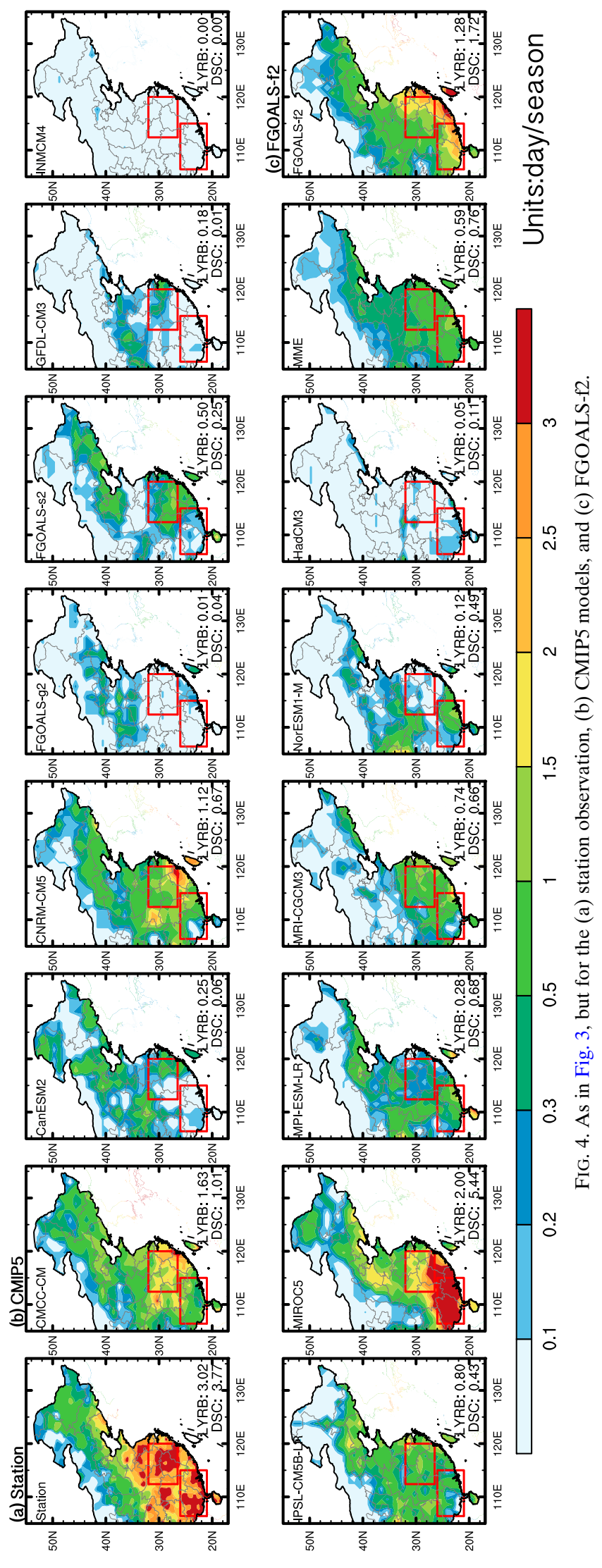




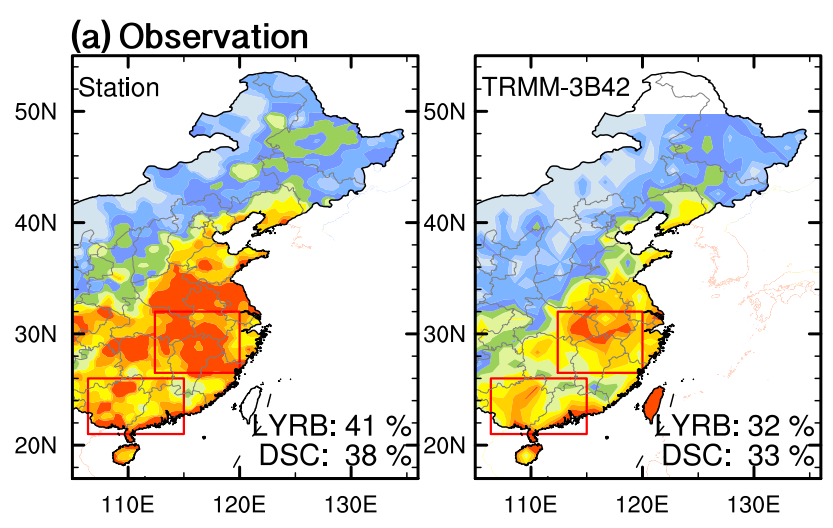

\section{(b) Combined gridded observation}

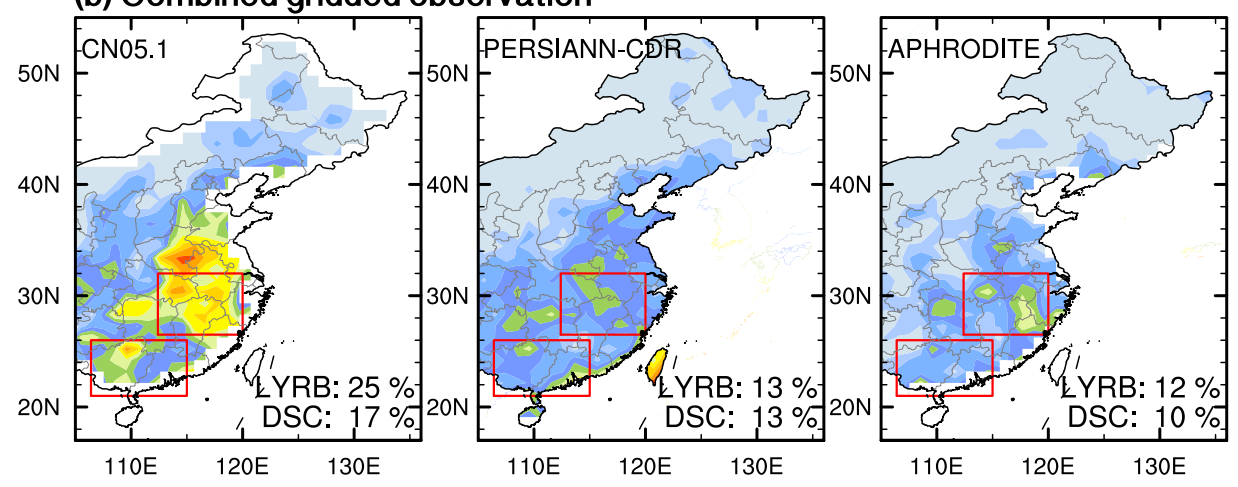

\section{(c) Reanalysis}

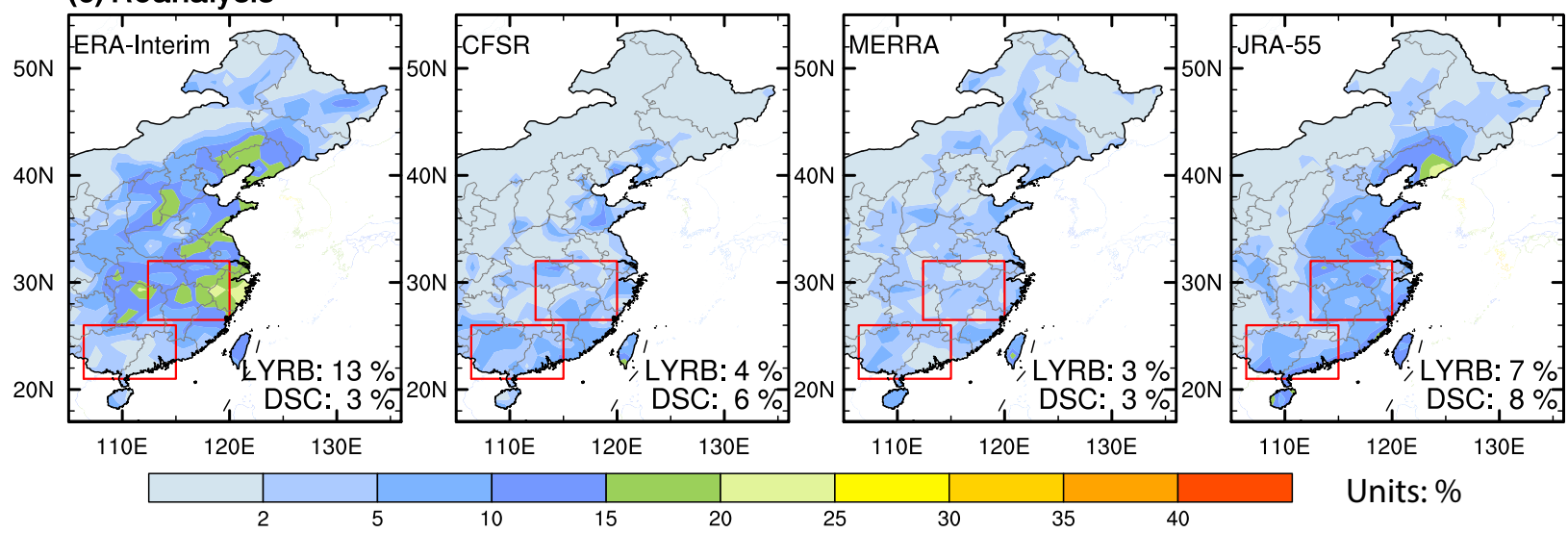

FIG. 5. Percentage of extreme precipitation relative to the total precipitation in the (a) observation, (b) combined gridded observation datasets, and (c) reanalysis datasets. The red boxes represent the two centers of maximum frequency of extreme precipitation: the LYRB center $\left(26.5^{\circ}-32^{\circ} \mathrm{N}, 112.5^{\circ}-120^{\circ} \mathrm{E}\right)$ and the DSC center $\left(21^{\circ}-26^{\circ} \mathrm{N}, 116.4^{\circ}-115^{\circ} \mathrm{E}\right)$. The numbers at the bottom right denote the domainaveraged percentage over the LYRB and DSC, respectively.

5 cannot capture rainfall events $>100 \mathrm{~mm} \mathrm{day}^{-1}, 9$ of the 13 models cannot capture rainfall $>150 \mathrm{~mm}^{-1}$ day $^{-1}$, and none of the models capture rainfall events $>$ $200 \mathrm{~mm} \mathrm{day}^{-1}$. CMCC-CM showed the best performance for extreme precipitation over East China. These biases are significantly improved in FGOALS-f2 (Fig. 2d). The frequency-intensity distribution in FGOALS-f2 is similar to that for the gauge observational datasets, and FGOALS-f2 captured extreme precipitation $>$ $200 \mathrm{~mm} \mathrm{day}^{-1}$.

\section{b. Spatial distribution of extreme precipitation frequency}

The spatial distribution of extreme precipitation over the whole summer season in east mainland China was examined. The gauge observational dataset and TRMM show 


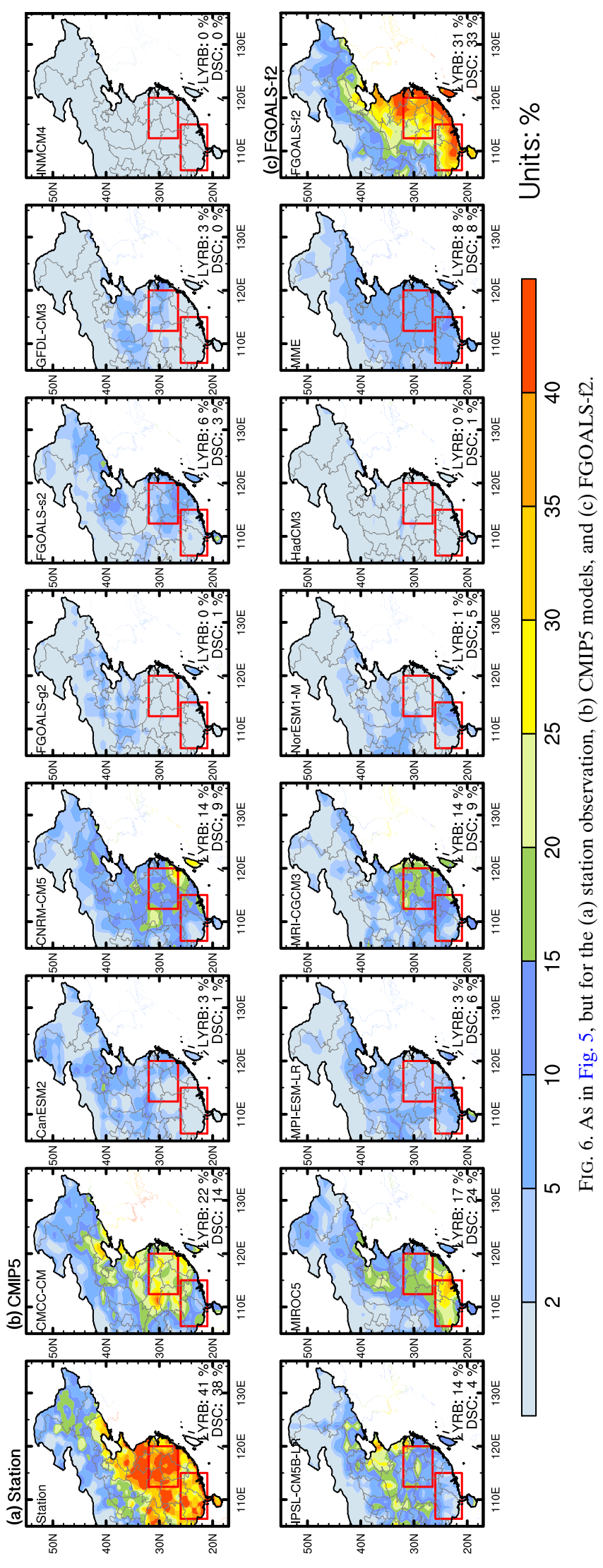


(a) Observation
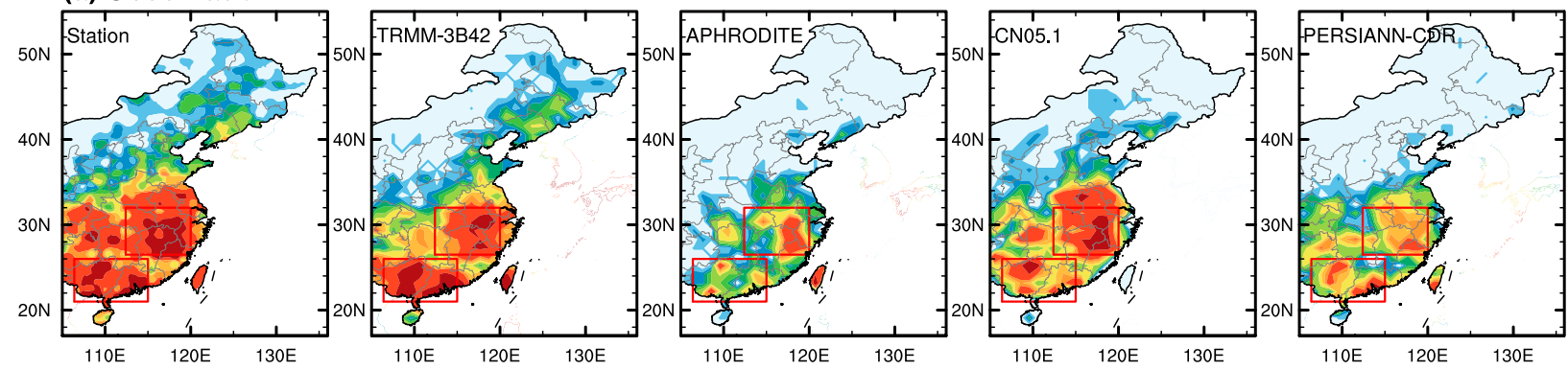

(b) Reanalysis
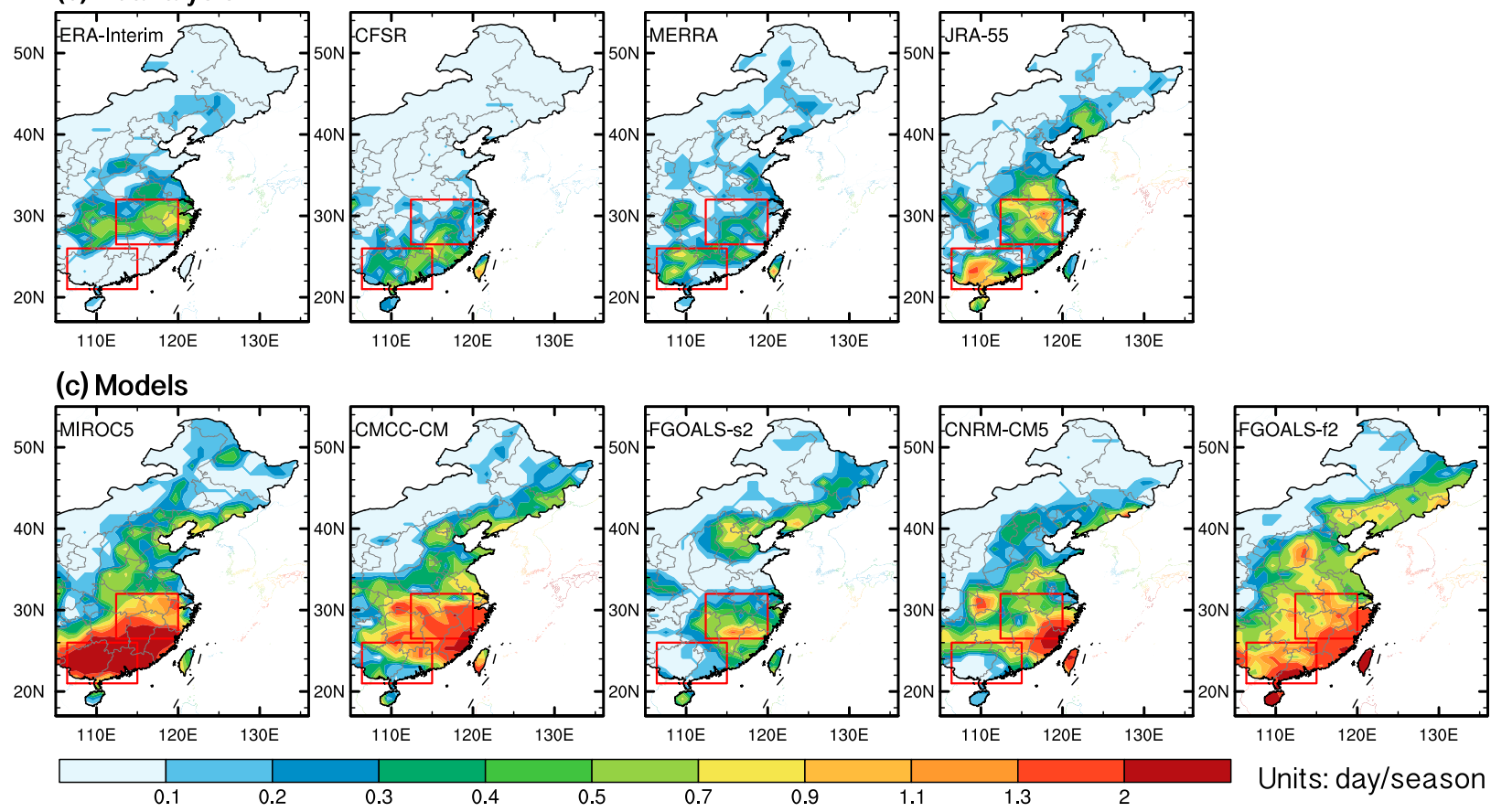

FIG. 7. Days of extreme precipitation over eastern China in the mei-yu season (from early June to mid-July). The red boxes represent the two centers of maximum frequency of extreme precipitation: the LYRB center $\left(26.5^{\circ}-32^{\circ} \mathrm{N}, 112.5^{\circ}-120^{\circ} \mathrm{E}\right)$ and the DSC center $\left(21^{\circ}-\right.$ $\left.26^{\circ} \mathrm{N}, 116.4^{\circ}-115^{\circ} \mathrm{E}\right)$.

two obvious centers of extreme precipitation over the lower-middle reach of Yangtze River basin (LYRB) and the deep South China region (DSC; Fig. 3a). Three combined gridded observational rainfall datasets reproduce these two centers (Fig. 3b), but the frequency of extreme precipitation over these two core regions is much lower than in the ground observation dataset. Among three combined gridded observational datasets, $\mathrm{CN} 05.1$ is the closest to the ground observation, accounting for twothirds of the gauge observation of extreme precipitation over the LYRB and one-third over DSC. By contrast, APHRODITE accounts for only one-third of the gauge observations of extreme precipitation over the LYRB and one-fifth of the events over DSC; the PERSIANNCDR dataset accounts for nearly two-fifths of the observed extreme precipitation over both regions.
In the reanalysis datasets (Fig. 3c), only the JRA-55 dataset reproduces the two centers of extreme precipitation, and the frequency of events over the two regions is smaller than in the observational datasets, reaching one-fourth of the gauge observation of extreme precipitation over the LYRB and two-fifths over DSC. The ERA-Interim dataset only reproduces the LYRB center of maximum frequency, with half the frequency of the observational datasets. The two major regions of extreme precipitation are almost absent in the MERRA and CFSR products.

Almost all the CMIP5 models are unable to realistically capture the two centers of extreme precipitation (Fig. 4), although a few models capture one center of maximum frequency of extreme precipitation. CMCC-CM, MRI-CGCM3, and GFDL CM3 only reproduce the LYRB 


\section{(a) Observation}
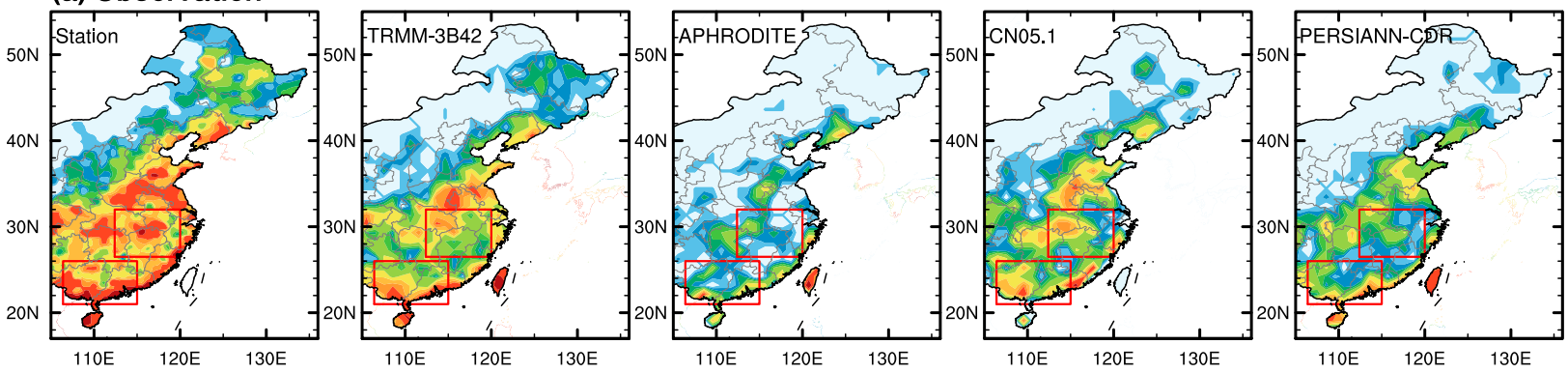

\section{(b) Reanalysis}
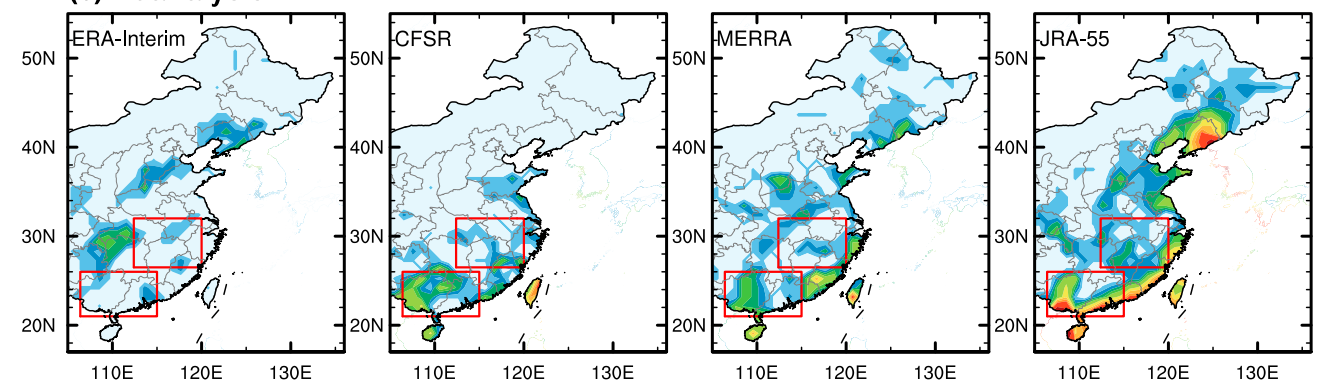

(c) Models

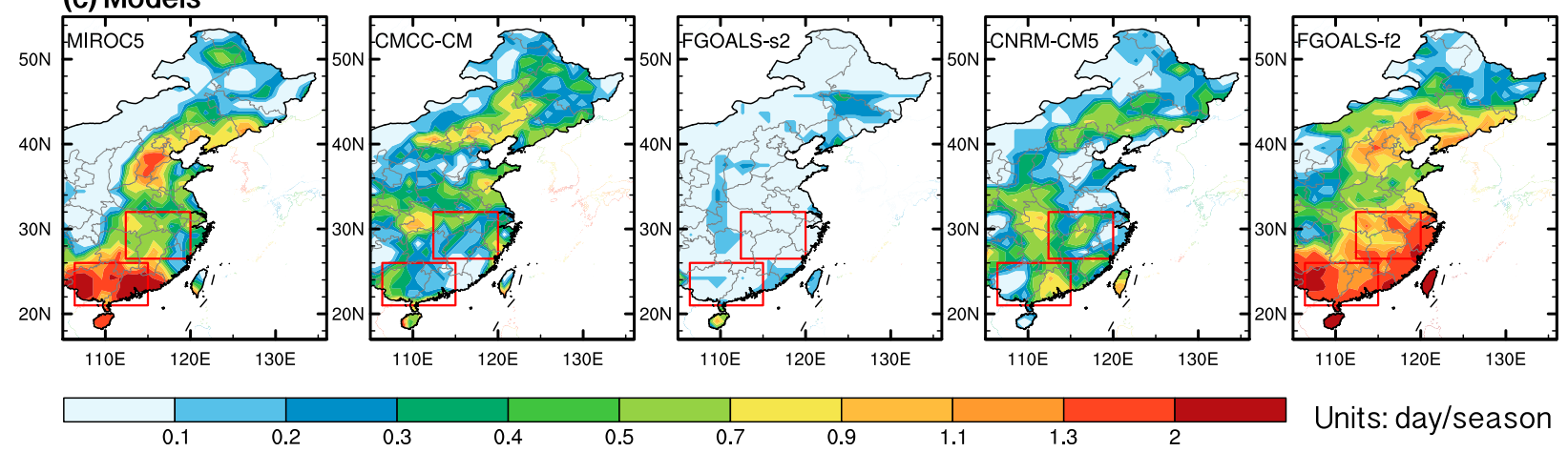

FIG. 8. As in Fig. 7, but for the late-summer typhoon season (from mid-July to late August).

region, whereas MIROC5 and NorESM1-M only simulate the DSC center. Almost all the CMIP5 models underestimate extreme precipitation over the LYRB and DSC, except MIROC5 overestimates the DSC center. The spatial distribution of extreme precipitation in FGOALS-f2 (Fig. 4) is not yet consistent with observations. The center of maximum frequency is located over coastal southeastern China, but the maximum center over the LYRB is almost absent in the FGOALS-f2 100-km version.

\section{c. Spatial distribution of the percent extreme precipitation amount}

The amount of extreme precipitation as a percentage of the total rainfall in JJA was also calculated (Figs. 5, 6 ). In terms of the two maximum-frequency centers defined in Figs. 3 and 4, the percentage of extreme precipitation in gauge and TRMM datasets reach almost $40 \%$ of total amount of precipitation. However, the contribution of extreme precipitation to the total amount of precipitation is underestimated in all the other datasets. The percentage of extreme precipitation is $<15 \%$ in three combined gridded observational rainfall products, except for CN05.1 with $25 \%$ of the total over the LYRB. In LYRB regions, the percentage of extreme precipitation is only $3 \%-15 \%$ in the reanalysis datasets, $<35 \%$ of that in the observational datasets. In DSC regions, the percentage of extreme precipitation ranges from $3 \%$ to $12 \%$ in the reanalysis datasets, $<30 \%$ of that in the observational datasets.

All the CMIP5 models underestimate the contribution of extreme precipitation to the total amount of rainfall (Fig. 6), although the simulation of the centers of maximum rainfall is consistent with the frequency in each model (Fig. 4). The percentages are $<10 \%$ in most of the CMIP5 models. Although MIROC5 overestimates the 


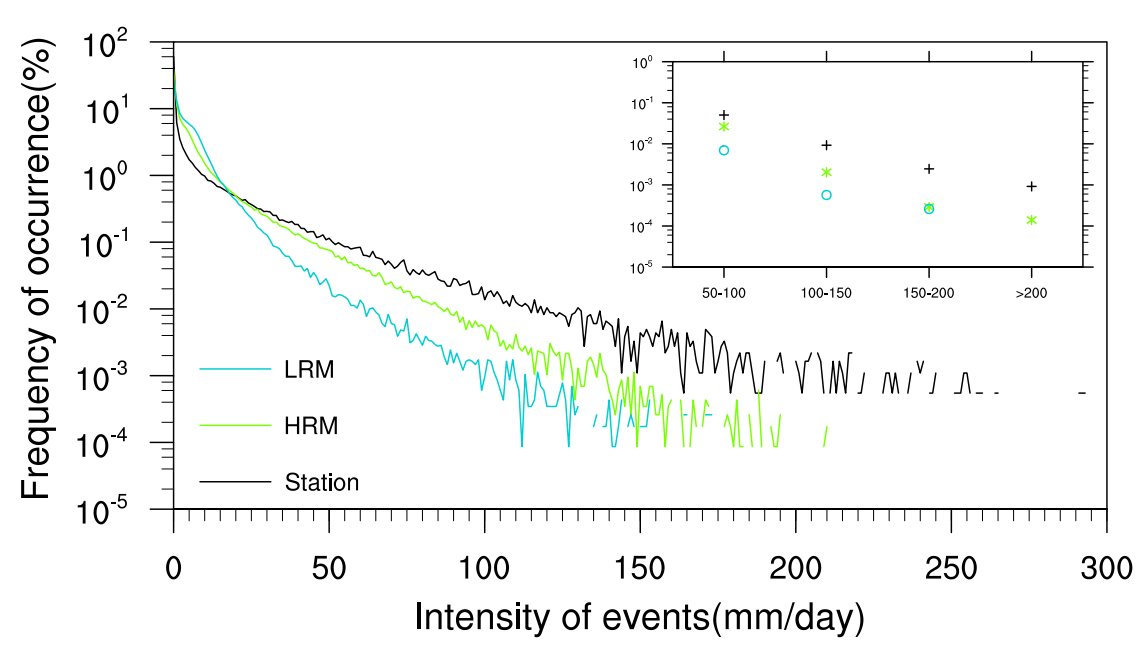

FIG. 9. Distribution of the summer (JJA) rainfall frequency-intensity in the high- and lowresolution CMIP5 models. The domain is eastern China in the region $105^{\circ}-140^{\circ} \mathrm{E}, 15^{\circ}-35^{\circ} \mathrm{N}$.

center of extreme precipitation in DSC for frequency of events (Fig. 4), the amount of extreme precipitation over DSC is $24 \%$ of the total rainfall, only about $60 \%$ of that in the observational datasets. The higher frequency and the lower percentage of extreme precipitation in MIROC5 should be related with the lower rainfall intensity for each extreme rainfall event of the simulation (Fig. 2). CMCC$\mathrm{CM}$, which has the best performance in the frequencyintensity distribution (Fig. 2), also reproduces the LYRB center of maximum percentage of extreme precipitation. The amount of extreme precipitation over the LYRB in this model is $22 \%$ of the total amount of rainfall and accounted for half that in the observational datasets. By contrast, the percentage of extreme precipitation has been generally improved in FGOALS-f2, which can reach up to $30 \%-$ $35 \%$, close to the observational datasets. However, the center of maximum rainfall in the FGOALS- 2 dataset is only seen over coastal southern China and is absent over the LYRB.

\section{Discussion}

The causes for differences in the extreme precipitation between different observation datasets (CN05.1, PERSIANN-CDR, and APHRODITE) may be related with their different data sources and production algorithm (Pendergrass and Hartmann 2014; Herold et al. 2016, 2017). For example, gridded rain gauges are actually derived from (single point) station observations, and satellite products over land include both satellite retrievals and gauge information. Combined gridded observation outputs derive from different data sources and algorithms, which is illustrated in section 2 .
Compared with station datasets, the reasons for the differences in the extreme precipitation between the reanalysis and models are mostly dependent on models. We will focus on the following discussion with reference to the seasonal/subseasonal mean observations, the resolution of the models, and the differences in the simulation of moisture and heat.

\section{a. Relationship between reanalysis and models' spatial distribution of extreme precipitation and their summer subseasonal progressions}

Previous studies have shown that the rain belt over East China shows a significant subseasonal progression in the boreal summer season (e.g., Tao and Chen 1987; Ding 1994). It was therefore speculated that whether the models can represent the two centers of the maximum extreme precipitation (LYRB and DSC) may be associated with the subseasonal progression of rainfall in the different datasets. The summer season was therefore divided into two separate periods: the mei-yu season from early June to mid-July (Fig. 7) and the typhoon season from mid-July to late August (Fig. 8). The results show that the datasets that capture the LYRB center of maximum rainfall are better able to simulate the rainfall in the mei-yu season, whereas the datasets that capture the DSC center of maximum rainfall exhibited more realistic results in the latesummer typhoon season. For example, CMCC-CM can simulate extreme precipitation in the mei-yu season but is unable to capture extreme precipitation in the summer typhoon season, corresponding to its single center of extreme precipitation over the LYRB (Fig. 4). MIROC5 is able to simulate extreme precipitation over DSC in the summer typhoon season but fails to reproduce 


\section{(a) Extreme precipitation frequency (units: day/season)}

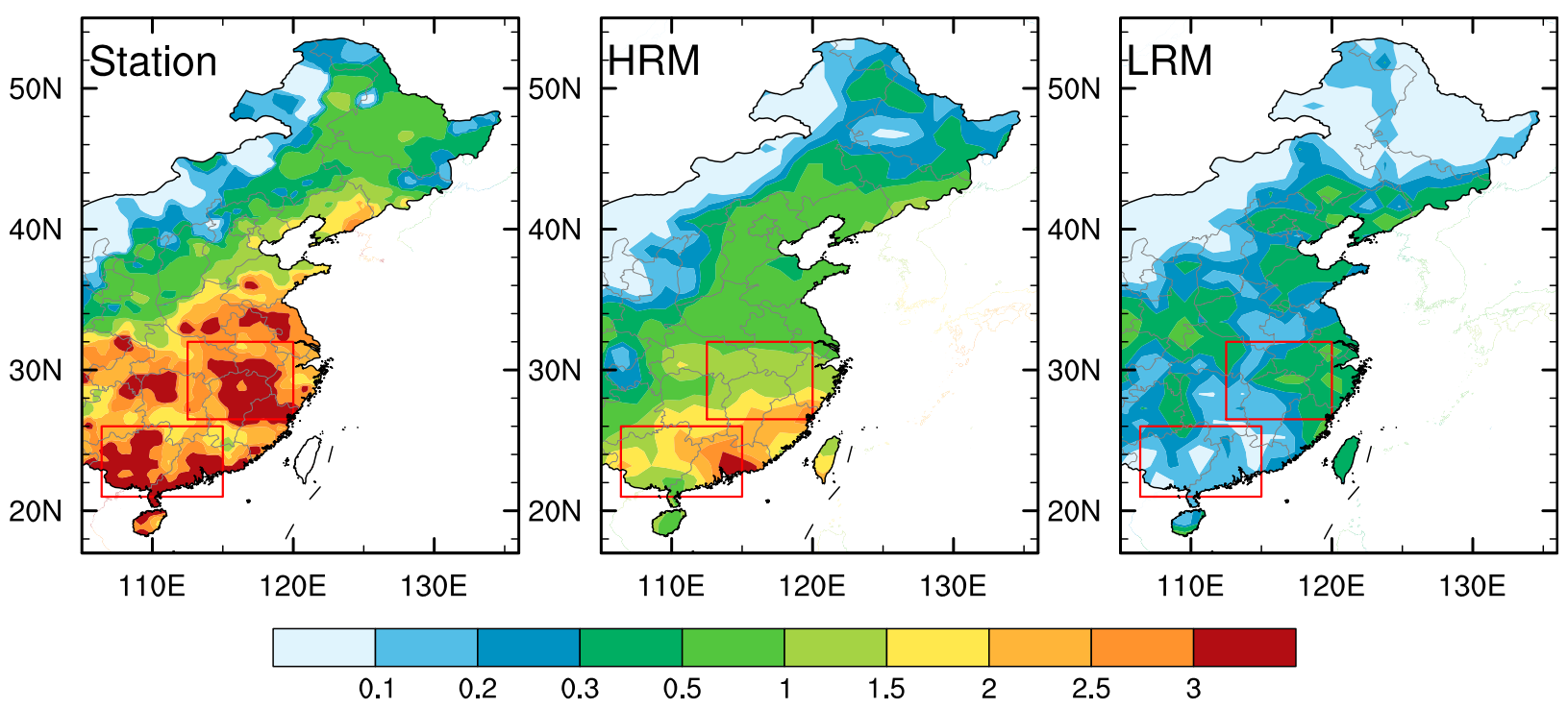

\section{(b) Extreme precipitation percentage (units:\%)}

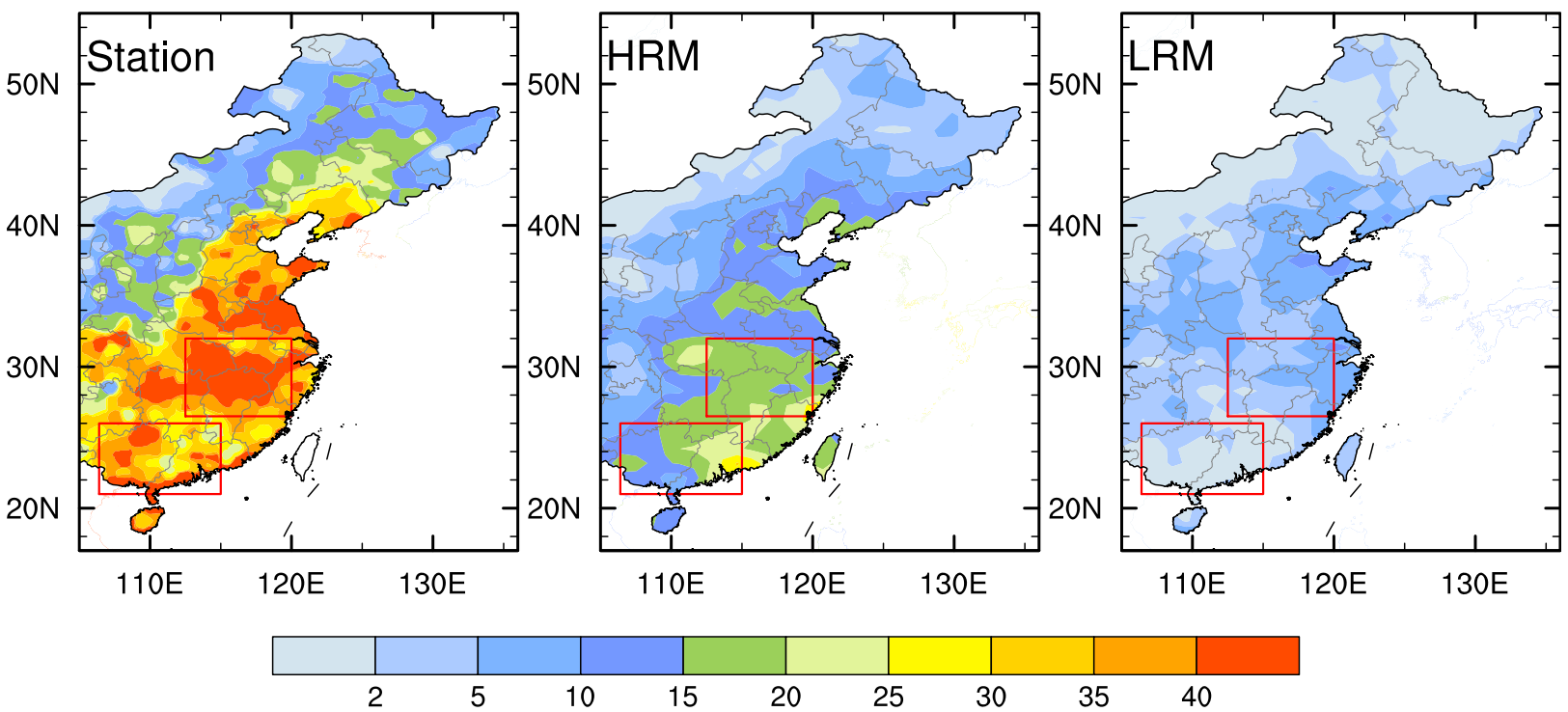

FIG. 10. Spatial distribution of the (a) frequency of extreme precipitation and (b) percentage of station observations with extreme precipitation in the high- and low-resolution CMIP5 models.

the center of maximum rainfall over the LYRB in the mei-yu season, corresponding to its single center of extreme precipitation over the DSC (Fig. 4). FGOALS-f2 is unable to capture the mei-yu rainfall season over the LYRB and therefore fails to reproduce the maximum in extreme precipitation over the LYRB. However, FGOALS-f2 is able to reproduce extreme precipitation over coastal southern China in the typhoon season, which may be attributed to the realistic simulation of tropical cyclones over the western Pacific ( $\mathrm{Li}$ and
Bao 2018, manuscript submitted to J. Adv. Model. Earth Syst.).

\section{b. Relationship between models' representation of} extreme precipitation and their horizontal resolution

Although all the model outputs were regridded to the same horizontal resolution, their original resolutions were different. To examine whether the simulation of extreme precipitation is dependent on the original spatial horizontal resolution, the CMIP5 models were 
a) CN05.1/ERA-Interim

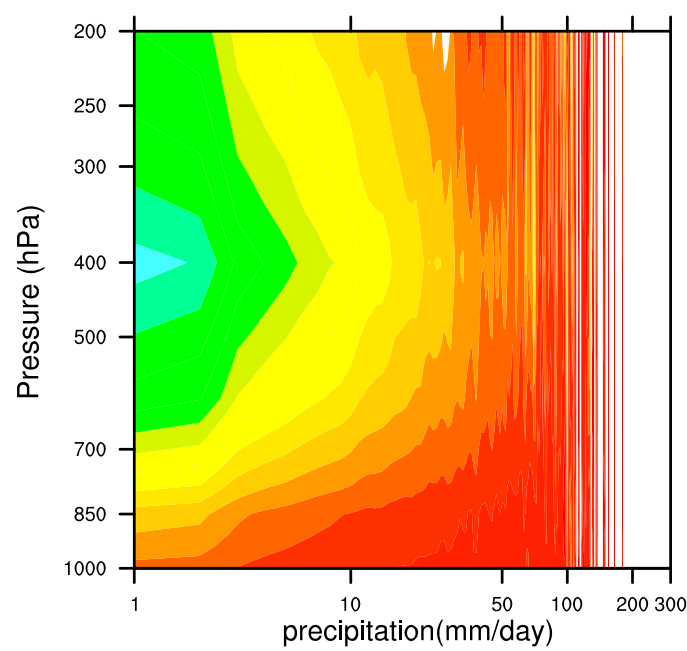

c) NorESM1-M

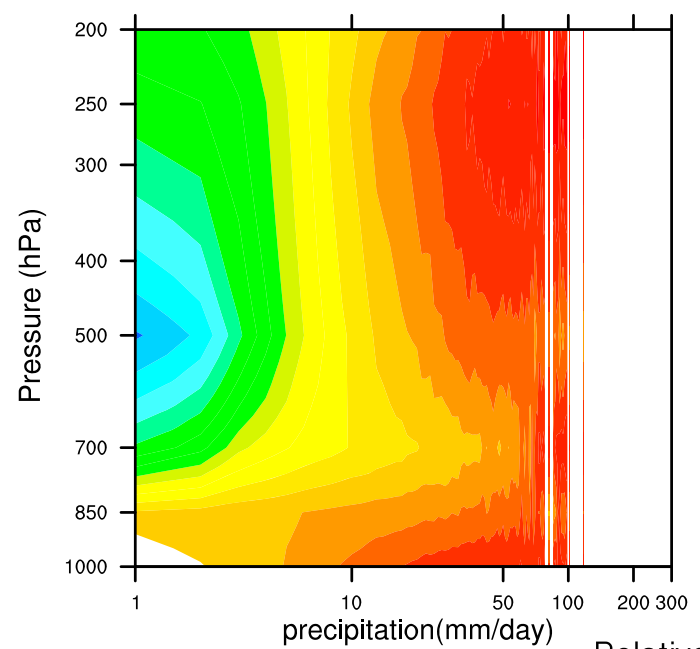

b) FGOALS-f2

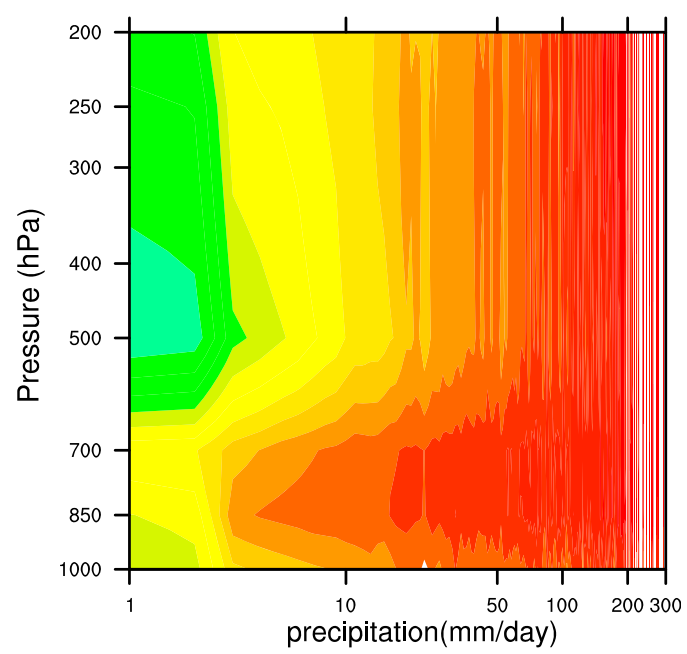

d) MIROC5

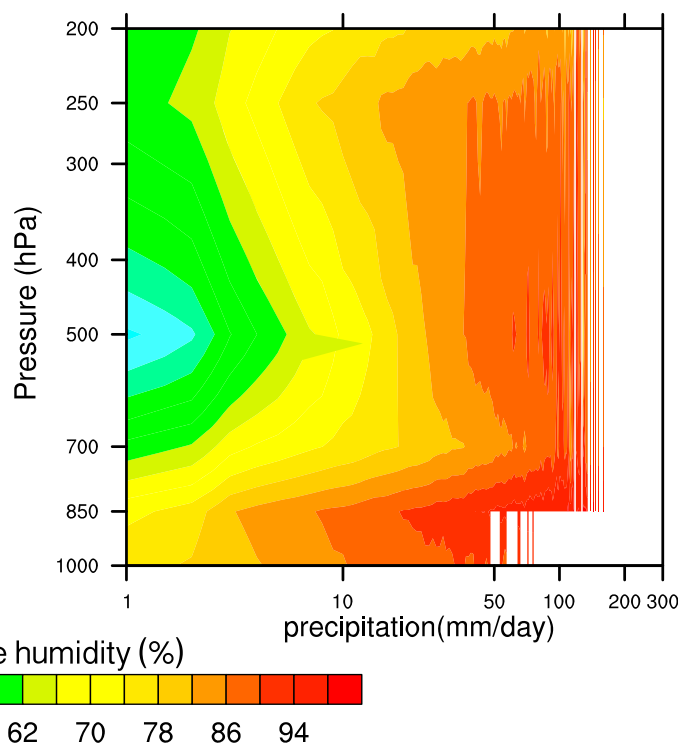

FIG. 11. Composite vertical profiles of relative humidity based on precipitation intensity in the (a) CN05.1/ERAInterim, (b) FGOALS-f2, (c) NorESM1-M, and (d) MIROC5 models over the DSC center of maximum rainfall $\left(26.5^{\circ}-32^{\circ} \mathrm{N}, 112.5^{\circ}-120^{\circ} \mathrm{E}\right)$.

categorized into two types: models with a horizontal resolution less than $1.5^{\circ} \times 1.5^{\circ}(\mathrm{CMCC}-\mathrm{CM}, \mathrm{MRI}-\mathrm{CGCM} 3$, CNRM-CM5, and MIROC5) were defined as highresolution models (HRMs), and those with a horizontal resolution greater than $2^{\circ} \times 2^{\circ}$ (GFDL CM3, IPSL-CM5B-LR, CanESM2, and HadCM3) were defined as low-resolution models (LRMs).

In terms of the frequency-intensity distribution, the HRMs perform better than the LRMs (Fig. 9). The HRMs do not capture rainfall intensities $>200 \mathrm{~mm} \mathrm{day}^{-1}$, whereas the LRMs do not capture rainfall intensities > $150 \mathrm{~mm} \mathrm{day}^{-1}$. For the intensities between 50 and $100 \mathrm{~mm} \mathrm{day}^{-1}$, the frequency captured by the HRMs is nearly $3 \times 10^{-2}$, about $50 \%$ of the observed frequency, whereas that of the LRMs is nearly $6 \times 10^{-3}$, about $10 \%$ of the observed frequency. Figure 10 shows the spatial distribution of the results. The HRMs perform better for both the percentage and frequency of extreme precipitation over east mainland China.

\section{c. Relationship between models' representation of extreme precipitation and their vertical profiles of moisture and heating rate}

Previous studies have shown that the simulation of convective rainfall is associated with the vertical profiles of the moisture content of the atmosphere (Holloway and Neelin 

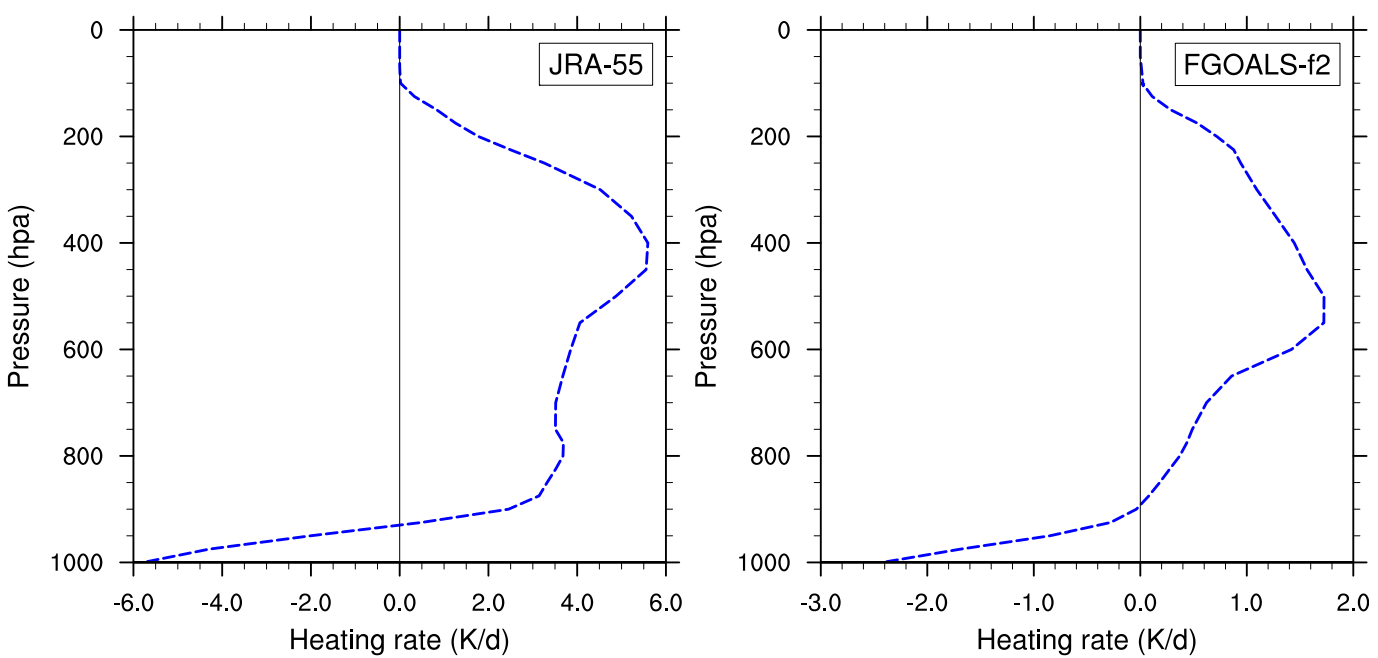

FIG. 12. Vertical profile of heating rate in the JRA-55 and FGOALS-f2 over the DSC center of maximum rainfall $\left(26.5^{\circ}-32^{\circ} \mathrm{N}, 112.5^{\circ}-120^{\circ} \mathrm{E}\right)$.

2009; Kim et al. 2014) and the heating rate (Li et al. 2009; Ling and Zhang 2013). The association of the vertical distribution of moisture and heating rate with the simulation of extreme precipitation was therefore investigated. In the period of JJA in 1998-2005, 736 days of daily precipitation and daily relative humidity were composed. The two CMIP5 models with the worst (NorESM1-M) and best (MIROC5) performance for extreme precipitation over DSC were selected, and FGOALS-f2 was also analyzed (Fig. 11). The composite of the CN05.1 precipitation with the ERAInterim relative humidity (CN05.1/ERA-Interim) was taken as the observation. Extreme precipitation, which is associated with strong, deep convection, only occurs when a deep layer of the air column is almost saturated and the lower troposphere above the boundary layer experiences sufficient moistening (Kim et al. 2014). Both MIROC5 and NorESM1-M showed insufficient moisture in the lower troposphere (between 850 and $600 \mathrm{hPa}$ ), but excessive moisture in the upper troposphere (between 400 and $200 \mathrm{hPa}$ ). Compared with NorESM1-M, the MIROC5 output is drier in the upper troposphere and wetter in the lower troposphere in accordance with a more realistic simulation of extreme precipitation. FGOALS-f2 shows a more realistic distribution of moisture than the other models, with drier upper troposphere and wetter lower troposphere. Therefore, FGOALS-f 2 can capture more extreme precipitation than the other CMIP5 models. This comparison indicates that the simulation of extreme precipitation is closely related to the realistic simulation of the moisture profile in the troposphere.

Heating in the lower troposphere causes the upward movement and convergence of water vapor, which is conducive to the generation and maintenance of deep convection ( $\mathrm{Li}$ et al. 2009). The heating profile of JRA55 and FGOALS-f2 over DSC were compared (Fig. 12). The observational profile shows positive vertical heating throughout the whole troposphere with a single peak at about $500 \mathrm{hPa}$ (Lin et al. 2004). By contrast, the JRA-55 model shows maximum warming extending throughout the troposphere from 850 to $300 \mathrm{hPa}$, rather than a single peak at lower levels. FGOALS-f2 gave a more realistic performance with a single heating maximum in the lower troposphere (about $550 \mathrm{hPa}$ ), indicating that FGOALS-f 2 may better facilitate the generation of deep convection (Lin et al. 2004; Li et al. 2009; Ling and Zhang 2013).

\section{Conclusions}

Realistic reproduction of historical extreme precipitation is a challenging but important issue in both reanalysis datasets and GCMs, especially over east mainland China. This study evaluated the current performance of combined gridded observational datasets, reanalysis datasets, and GCMs (CMIP5 and FGOALS-f2) for extreme precipitation over east mainland China. Gauge observation was used as the observational data. Compared with the observations, all the combined gridded datasets (CN05.1, APHRODITE, and PERSIANN-CDR), all the reanalysis datasets (ERA-Interim, JRA-55, MERRA, and CFSR), and most of the CMIP5 models are unable to capture extreme precipitation $>150 \mathrm{~mm} \mathrm{day}^{-1}$ based on the analysis of the intensity-frequency distribution. All the datasets underestimate the frequency of heavy rainfall over east mainland China. The newly released FGOALS-f2 
TABLE 2. Ability of the datasets to reproduce extreme precipitation.

\begin{tabular}{|c|c|c|c|c|c|c|c|}
\hline \multirow[b]{2}{*}{ Dataset } & & \multicolumn{4}{|c|}{$\begin{array}{l}\text { Frequency-intensity distribution } \\
\qquad\left(\mathrm{mm} \mathrm{day}^{-1}\right)\end{array}$} & \multicolumn{2}{|c|}{$\begin{array}{c}\text { Spatial } \\
\text { distribution }\end{array}$} \\
\hline & & $>50$ & $>100$ & $>150$ & $>200$ & LYRB & DSC \\
\hline \multirow[t]{2}{*}{ Observational datasets } & Station & $\checkmark$ & $\checkmark$ & $\checkmark$ & $\checkmark$ & $\checkmark$ & $\checkmark$ \\
\hline & TRMM & $\checkmark$ & $\checkmark$ & $\checkmark$ & $\checkmark$ & $\checkmark$ & $\checkmark$ \\
\hline \multirow[t]{3}{*}{ Combined gridded observational datasets } & APHRODITE & $\checkmark$ & $\checkmark$ & - & - & $\checkmark$ & $\checkmark$ \\
\hline & CN05.1 & $\checkmark$ & $\checkmark$ & - & - & $\checkmark$ & $\checkmark$ \\
\hline & PERSIANN-CDR & $\checkmark$ & $\checkmark$ & - & - & $\checkmark$ & $\checkmark$ \\
\hline \multirow[t]{4}{*}{ Reanalysis datasets } & JRA-55 & $\checkmark$ & - & - & - & $\checkmark$ & $\checkmark$ \\
\hline & MERRA & $\checkmark$ & $\checkmark$ & - & - & - & - \\
\hline & ERA-Interim & $\checkmark$ & $\checkmark$ & - & - & $\checkmark$ & - \\
\hline & CFSR & $\checkmark$ & $\checkmark$ & - & - & - & - \\
\hline \multirow[t]{14}{*}{ CMIP5 models } & CanESM2 & $\checkmark$ & $\checkmark$ & - & - & - & - \\
\hline & CMCC-CM & $\checkmark$ & $\checkmark$ & $\checkmark$ & - & $\checkmark$ & - \\
\hline & CNRM-CM5 & $\checkmark$ & $\checkmark$ & $\checkmark$ & - & - & - \\
\hline & FGOALS-g2 & $\checkmark$ & - & - & - & - & - \\
\hline & FGOALS-s2 & $\checkmark$ & - & - & - & - & - \\
\hline & GFDL CM3 & $\checkmark$ & $\checkmark$ & - & - & $\checkmark$ & - \\
\hline & HadCM3 & $\checkmark$ & - & - & - & - & - \\
\hline & INM-CM4.0 & $\checkmark$ & - & - & - & - & - \\
\hline & IPSL-CM5B-LR & $\checkmark$ & $\checkmark$ & $\checkmark$ & - & - & - \\
\hline & MIROC5 & $\checkmark$ & $\checkmark$ & - & - & - & $\checkmark$ \\
\hline & MPI-ESM-LR & $\checkmark$ & $\checkmark$ & - & - & - & - \\
\hline & MRI-CGCM3 & $\checkmark$ & $\checkmark$ & $\checkmark$ & - & $\checkmark$ & - \\
\hline & NorESM1-M & $\checkmark$ & - & - & - & - & - \\
\hline & MME & $\checkmark$ & $\checkmark$ & $\checkmark$ & - & - & - \\
\hline CAS FGOALS-f2 & FGOALS-f2 $100 \mathrm{~km}$ & $\checkmark$ & $\checkmark$ & $\checkmark$ & $\checkmark$ & - & - \\
\hline
\end{tabular}

significantly improves the intensity-frequency distribution of precipitation, giving similar results to the observational data, and is able to capture extreme precipitation $>$ $200 \mathrm{~mm} \mathrm{day}^{-1}$. With respect to the spatial distribution of rainfall, two centers of maximum extreme precipitation were identified in the observations over the LYRB and DSC. The combined gridded observations and the JRA-55 capture these two centers, but the ERA-Interim, MERRA, and CFSR datasets and almost all the CMIP5 models are unable to capture the two centers simultaneously. The ERA-Interim dataset and a few of the CMIP5 models capture a single center of maximum rainfall. The percentage of the total rainfall occurring in extreme precipitation is generally underestimated by $25 \%-75 \%$ in all the datasets except for FGOALS-f2 (Table 2).

Two regions of maximum extreme precipitation are closely related to rainfall in the mei-yu and typhoon seasons, respectively. Although the simulation of extreme precipitation is largely influenced by the horizontal resolution of the models, physical parameterization may have a more important role, particularly for heavy rainfall $>150 \mathrm{~mm} \mathrm{day}^{-1}$. A better performance in simulating extreme precipitation also depends on the realistic simulation of the vertical moisture profile and vertical distribution of the heating rate. FGOALS-f2 shows a better performance for modeling extreme precipitation because of its higher resolution and more realistic physics.

This work provides a fundamental evaluation of extreme precipitation in current compiled datasets and reanalysis datasets over east mainland China and also provides a reference for the selection of models in future reliable projections of extreme precipitation over east mainland China. Although this study indicates ways to improve models' performance in representing extreme rainfall, the factors affecting the simulation of extreme precipitation still requires further investigation using numerical modeling experiments.

Acknowledgments. This study is supported by funds from the National Key Research and Development Program-Global Change and Mitigation Project (Grant 2016YFA0602401) and National Natural Science Foundation of China (91737306, 41775071, and 41621061).

\section{REFERENCES}

Accadia, C., S. Mariani, M. Casaioli, A. Lavagnini, and A. Speranza, 2003: Sensitivity of precipitation forecast skill scores to bilinear interpolation and a simple nearest-neighbor average method on high-resolution verification grids. Wea. Forecasting, 18, 918-932, https://doi.org/10.1175/1520-0434(2003)018<0918: SOPFSS $>2.0 . \mathrm{CO} ; 2$. 
Ashouri, H., K.-L. Hsu, S. Sorooshian, D. K. Braithwaite, K. R. Knapp, L. D. Cecil, B. R. Nelson, and O. P. Prat, 2015: PERSIANN-CDR: Daily precipitation climate data record from multisatellite observations for hydrological and climate studies. Bull. Amer. Meteor. Soc., 96, 69-83, https://doi.org/ 10.1175/BAMS-D-13-00068.1.

Cao, G., and G. J. Zhang, 2017: Role of vertical structure of convective heating in MJO simulation in NCAR CAM5.3. J. Climate, 30, 7423-7439, https://doi.org/10.1175/JCLI-D-16-0913.1.

Chan, S. C., E. J. Kendon, H. J. Fowler, S. Blenkinsop, C. A. T. Ferro, and D. B. Stephenson, 2013: Does increasing the spatial resolution of a regional climate model improve the simulated daily precipitation? Climate Dyn., 41, 1475-1495, https://doi.org/ 10.1007/s00382-012-1568-9.

Chen, H., and J. Sun, 2017: Contribution of human influence to increased daily precipitation extremes over China. Geophys. Res. Lett., 44, 2436-2444, https://doi.org/10.1002/2016GL072439.

Dai, A., 2006: Precipitation characteristics in eighteen coupled climate models. J. Climate, 19, 4605-4630, https://doi.org/ 10.1175/JCLI3884.1.

Dee, D. P., and Coauthors, 2011: The ERA-Interim reanalysis: Configuration and performance of the data assimilation system. Quart. J. Roy. Meteor. Soc., 137, 553-597, https://doi.org/ 10.1002/qj.828.

Deng, X., A. Ye, Y. Mao, Y. Lang, and J. Xu, 2015: TRMM precipitation evaluation for inland of China. Shuiwen, 35, 47-54, 61.

Ding, Y., 1994: Monsoons over China. Adv. Atmos. Sci., 11, 252252, https://doi.org/10.1007/BF02666553.

Easterling, D. R., J. L. Evans, P. Ya. Groisman, T. R. Karl, K. E. Kunkel, and P. Ambenje, 2000: Observed variability and trends in extreme climate events: A brief review. Bull. Amer. Meteor. Soc., 81, 417-425, https://doi.org/10.1175/1520-0477(2000)081<0417: OVATIE $>2.3 . \mathrm{CO} ; 2$.

Emori, S., A. Hasegawa, T. Suzuki, and K. Dairaku, 2005: Validation, parameterization dependence, and future projection of daily precipitation simulated with a high-resolution atmospheric GCM. Geophys. Res. Lett., 32, L06708, https://doi.org/ 10.1029/2004GL022306.

Gao, X., Y. Xu, Z. Zhao, J. S. Pal, and F. Giorgi, 2006: On the role of resolution and topography in the simulation of East Asia precipitation. Theor. Appl. Climatol., 86, 173-185, https://doi.org/ 10.1007/s00704-005-0214-4.

Haarsma, R. J., and Coauthors, 2016: High Resolution Model Intercomparison Project (HighResMIP v1.0) for CMIP6. Geosci. Model Dev., 9, 4185-4208, https://doi.org/10.5194/gmd-9-4185-2016.

Hagos, S., and Coauthors, 2010: Estimates of tropical diabatic heating profiles: Commonalities and uncertainties. J. Climate, 23, 542-558, https://doi.org/10.1175/2009JCLI3025.1.

Herold, N., L. V. Alexander, M. G. Donat, S. Contractor, and A. Becker, 2016: How much does it rain over land? Geophys. Res. Lett., 43, 341-348, https://doi.org/10.1002/2015GL066615.

—, A. Behrangi, and L. V. Alexander, 2017: Large uncertainties in observed daily precipitation extremes over land. J. Geophys. Res. Atmos., 122, 668-681, https://doi.org/10.1002/ 2016JD025842.

Holloway, C. E., and J. D. Neelin, 2009: Moisture vertical structure, column water vapor, and tropical deep convection. J. Atmos. Sci., 66, 1665-1683, https://doi.org/10.1175/2008JAS2806.1.

Huang, A., Y. Zhang, and J. Zhu, 2009: Effects of the physical process ensemble technique on simulation of summer precipitation over China. Acta Meteor. Sin., 23, 713-724.

Huang, D.-Q., J. Zhu, Y.-C. Zhang, and A.-N. Huang, 2013: Uncertainties on the simulated summer precipitation over eastern China from the CMIP5 models. J. Geophys. Res., 118, 9035-9047, https://doi.org/10.1002/jgrd.50695.

- , P. Yan, J. Zhu, Y. Zhang, X. Kuang, and J. Cheng, 2017: Uncertainty of global summer precipitation in the CMIP5 models: A comparison between high-resolution and low-resolution models. Theor. Appl. Climatol., 132, 55-69, https://doi.org/ 10.1007/s00704-017-2078-9.

Huffman, G. J., and Coauthors, 2007: The TRMM Multisatellite Precipitation Analysis (TMPA): Quasi-global, multiyear, combined-sensor precipitation estimates at fine scales. $J$. Hydrometeor., 8, 38-55, https://doi.org/10.1175/JHM560.1.

Jiang, Z., W. Li, J. Xu, and L. Li, 2015: Extreme precipitation indices over China in CMIP5 models. Part I: Model evaluation. J. Climate, 28, 8603-8619, https://doi.org/10.1175/JCLI-D-15-0099.1.

Kim, D., and Coauthors, 2014: Process-oriented MJO simulation diagnostic: Moisture sensitivity of simulated convection. J. Climate, 27, 5379-5395, https://doi.org/10.1175/JCLI-D-13-00497.1.

Kimoto, M., N. Yasutomi, C. Yokoyama, and S. Emori, 2005: Projected changes in precipitation characteristics around Japan under the global warming. SOLA, 1, 85-88, https://doi.org/ 10.2151/sola.2005-023.

Kobayashi, S., and Coauthors, 2015: The JRA-55 Reanalysis: General specifications and basic characteristics. J. Meteor. Soc. Japan, 93, 5-48, https://doi.org/10.2151/jmsj.2015-001.

Lesk, C., P. Rowhani, and N. Ramankutty, 2016: Influence of extreme weather disasters on global crop production. Nature, 529, 84-87, https://doi.org/10.1038/nature16467.

Li, C., X. Jia, J. Ling, W. Zhou, and C. Zhang, 2009: Sensitivity of MJO simulations to diabatic heating profiles. Climate Dyn., 32, 167-187, https://doi.org/10.1007/s00382-008-0455-x.

Li, J., and B. Wang, 2017: Predictability of summer extreme precipitation days over eastern China. Climate Dyn., https://doi.org/ 10.1007/s00382-017-3848-x, in press.

Li, L., W. Li, T. Ballard, G. Sun, and M. Jeuland, 2016: CMIP5 model simulations of Ethiopian Kiremt-season precipitation: Current climate and future changes. Climate Dyn., 46, 28832895, https://doi.org/10.1007/s00382-015-2737-4.

Lin, J., B. Mapes, M. Zhang, and M. Newman, 2004: Stratiform precipitation, vertical heating profiles, and the Madden-Julian oscillation. J. Atmos. Sci., 61, 296-309, https://doi.org/10.1175/ 1520-0469(2004)061<0296:SPVHPA > 2.0.CO;2.

Lin, S.-J., 2004: A "vertically Lagrangian" finite-volume dynamical core for global models. Mon. Wea. Rev., 132, 2293-2307, https:// doi.org/10.1175/1520-0493(2004)132<2293:AVLFDC >2.0.CO;2. and R. B. Rood, 1996: Multidimensional flux-form semi-Lagrangian transport schemes. Mon. Wea. Rev., 124, 2046-2070, https:// doi.org/10.1175/1520-0493(1996)124<2046:MFFSLT>2.0.CO;2.

Lin, Y., M. Zhao, Y. Ming, J.-C. Golaz, L. J. Donner, S. A. Klein, V. Ramaswamy, and S. Xie, 2013: Precipitation partitioning, tropical clouds, and intraseasonal variability in GFDL AM2. J. Climate, 26, 5453-5466, https://doi.org/10.1175/ JCLI-D-12-00442.1.

Ling, J., and C. Zhang, 2013: Diabatic heating profiles in recent global reanalyses. J. Climate, 26, 3307-3325, https://doi.org/ 10.1175/JCLI-D-12-00384.1.

Liu, X., and Z. Ren, 2005: Progress in quality control of surface meteorological data. Mater. Sci. Technol., 33, 199-203.

Ma, S., T. Zhou, A. Dai, and Z. Han, 2015: Observed changes in the distributions of daily precipitation frequency and amount over China from 1960 to 2013. J. Climate, 28, 6960-6978, https:// doi.org/10.1175/JCLI-D-15-0011.1.

Matsumoto, J., and K. Takahashi, 1999: Regional differences of daily rainfall characteristics in East Asian summer monsoon 
season. Geogr. Rev. Japan, 72B, 193-201, https://doi.org/ 10.4157/grj1984b.72.193.

Meehl, G. A., and Coauthors, 2000: An introduction to trends in extreme weather and climate events: Observations, socioeconomic impacts, terrestrial ecological impacts, and model projections. Bull. Amer. Meteor. Soc., 81, 413-416, https://doi.org/10.1175/ 1520-0477(2000)081<0413:AITTIE > 2.3.CO;2.

Miao, C., H. Ashouri, K.-L. Hsu, S. Sorooshian, and Q. Duan, 2015: Evaluation of the PERSIANN-CDR daily rainfall estimates in capturing the behavior of extreme precipitation over China. J. Hydrometeor., 16, 1387-1396, https://doi.org/10.1175/JHMD-14-0174.1.

Murata, A., and M. Ueno, 2005: The vertical profile of entrainment rate simulated by a cloud-resolving model and application to a cumulus parameterization. J. Meteor. Soc. Japan, 83, 745-770, https://doi.org/10.2151/jmsj.83.745.

Murray, V., and K. L. Ebi, 2012: IPCC Special Report on Managing the Risks of Extreme Events and Disasters to Advance Climate Change Adaptation (SREX). J. Epidemiol. Community Health, 66, 759-760, https://doi.org/10.1136/jech-2012-201045.

Ou, T., D. Chen, H. W. Linderholm, and J.-H. Jeong, 2013: Evaluation of global climate models in simulating extreme precipitation in China. Tellus, 65A, 19799, https://doi.org/10.3402/ tellusa.v65i0.19799.

Pendergrass, A. G., and D. L. Hartmann, 2014: Two modes of change of the distribution of rain. J. Climate, 27, 8357-8371, https://doi.org/10.1175/JCLI-D-14-00182.1.

Rienecker, M. M., and Coauthors, 2011: MERRA: NASA's Modern-Era Retrospective Analysis for Research and Applications. J. Climate, 24, 3624-3648, https://doi.org/10.1175/ JCLI-D-11-00015.1.

Saha, S., and Coauthors, 2010: The NCEP Climate Forecast System Reanalysis. Bull. Amer. Meteor. Soc., 91, 1015-1057, https:// doi.org/10.1175/2010BAMS3001.1.

Song, X., G. J. Zhang, and J.-L. F. Li, 2012: Evaluation of microphysics parameterization for convective clouds in the NCAR Community Atmosphere Model CAM5. J. Climate, 25, 85688590, https://doi.org/10.1175/JCLI-D-11-00563.1.

Stephens, G. L., and K. J. Wilson, 1980: The response of a deep cumulus convection model to changes in radiative heating. J. Atmos. Sci., 37, 421-434, https://doi.org/10.1175/1520-0469(1980) 037<0421:TROADC $>2.0$. CO;2.

Tao, S., and L. Chen, 1987: A review of recent research on the East Asian summer monsoon in China. Monsoon Meteorology, C.-P. Chang and T. N. Krishnamurti, Eds., Oxford University Press, 60-92.

Tokioka, T., K. Yamazaki, A. Kitoh, and T. Ose, 1988: The Equatorial 30-60 day oscillation and the Arakawa-Schubert penetrative cumulus parameterization. J. Meteor. Soc. Japan, 66, 883-901, https://doi.org/10.2151/jmsj1965.66.6_883.

Toreti, A., and Coauthors, 2013: Projections of global changes in precipitation extremes from Coupled Model Intercomparison Project Phase 5 models. Geophys. Res. Lett., 40, 4887-4892, https://doi.org/10.1002/grl.50940.

Wang, B., J. Liu, J. Yang, T. Zhou, and Z. Wu, 2009: Distinct principal modes of early and late summer rainfall anomalies in
East Asia. J. Climate, 22, 3864-3875, https://doi.org/10.1175/ 2009JCLI2850.1.

Wang, Y., G. J. Zhang, and Y.-J. He, 2017: Simulation of precipitation extremes using a stochastic convective parameterization in the NCAR CAM5 under different resolutions. J. Geophys. Res. Atmos., 122, 12 875-12 891, https://doi.org/ 10.1002/2017JD026901.

Wang, Y., and L. Zhou, 2005: Observed trends in extreme precipitation in China during 1961-2001 and the associated changes in large-scale circulation. Geophys. Res. Lett., 32, L09707, https://doi.org/10.1029/2005GL022574; Corrigendum, 32, L17708, https://doi.org/10.1029/2005GL023769.

Willmott, C. J., C. M. Rowe, and W. D. Philpot, 1985: Small-scale climate maps: A sensitivity analysis of some common assumptions associated with grid-point interpolation and contouring. Amer. Cartogr., 12, 5-16, https://doi.org/10.1559/ 152304085783914686.

Wu, J., and X.-J. Gao, 2013: A gridded daily observation dataset over China region and comparison with the other datasets (in Chinese). Chin. J. Geophys., 56, 1102-1111.

Yang, J., Q. Bao, B. Wang, D.-Y. Gong, H. He, and M.-N. Gao, 2014: Distinct quasi-biweekly features of the subtropical East Asian monsoon during early and late summers. Climate Dyn., 42, 1469-1486, https://doi.org/10.1007/s00382-013-1728-6.

Yatagai, A., O. Arakawa, K. Kamiguchi, H. Kawamoto, M. I. Nodzu, and A. Hamada, 2009: A 44-year daily gridded precipitation dataset for Asia based on a dense network of rain gauges. SOLA, 5, 137-140, https://doi.org/10.2151/sola.2009-035.

_ , K. Kamiguchi, O. Arakawa, A. Hamada, N. Yasutomi, and A. Kitoh, 2012: APHRODITE: Constructing a long-term daily gridded precipitation dataset for Asia based on a dense network of rain gauges. Bull. Amer. Meteor. Soc., 93, 1401-1415, https://doi.org/10.1175/BAMS-D-11-00122.1.

Zhai, P., X. Zhang, H. Wan, and X. Pan, 2005: Trends in total precipitation and frequency of daily precipitation extremes over China. J. Climate, 18, 1096-1108, https://doi.org/10.1175/ JCLI-3318.1.

Zhang, Y., and H. Chen, 2016: Comparing CAM5 and superparameterized CAM5 simulations of summer precipitation characteristics over continental East Asia: Mean state, frequency-intensity relationship, diurnal cycle, and influencing factors. J. Climate, 29, 1067-1089, https://doi.org/10.1175/ JCLI-D-15-0342.1.

,-- , and R. Yu, 2014: Simulations of stratus clouds over eastern China in CAM5: Sensitivity to horizontal resolution. J. Climate, 27, 7033-7052, https://doi.org/10.1175/ JCLI-D-13-00732.1.

Zhao, C.-Y., Y. Wang, X.-Y. Zhou, Y. Cui, Y.-L. Liu, D.-M. Shi, H.-M. Yu, and Y.-Y. Liu, 2013: Changes in climatic factors and extreme climate events in northeast China during 1961-2010. Adv. Climate Change Res., 4, 92-102, https://doi.org/10.3724/ SP.J.1248.2013.092.

Zhou, L., and Coauthors, 2015: Global energy and water balance: Characteristics from finite-volume atmospheric model of the IAP/LASG (FAMIL1). J. Adv. Model. Earth Syst., 7, 1-20, https://doi.org/10.1002/2014MS000349. 